\title{
Subprime Facts: \\ What (We Think) We Know about the Subprime Crisis and What We Don't
}

\section{Christopher L. Foote, Kristopher Gerardi, Lorenz Goette, and Paul S. Willen}

\begin{abstract}
:
Using a variety of datasets, we document some basic facts about the current subprime crisis. Many of these facts are applicable to the crisis at a national level, while some illustrate problems relevant only to Massachusetts and New England. We conclude by discussing some outstanding questions about which the data, we believe, are not yet conclusive.
\end{abstract}

JEL Classifications: D11, D12, G21, R20

Christopher Foote and Paul Willen are senior economists and policy advisors, Lorenz Goette is a senior economist, and Kristopher Gerardi is a research associate at the Federal Reserve Bank of Boston. Gerardi will join the Federal Reserve Bank of Atlanta in September as a research economist. Their email addresses are chris.foote@bos.frb.org, paul.willen@bos.frb.org, lorenz.goette@bos.frb.org, and kristopher.gerardi@bos.frb.org respectively.

We thank participants at various forums, summits, breakfasts, brownbags, seminars, and other gatherings for helpful comments and suggestions. We also thank Tim Warren and Alan Pasnik of The Warren Group, and Dick Howe Jr., the Register of Deeds of North Middlesex County, Massachusetts, for providing us with data, advice, and insight. Finally, we thank Elizabeth Murry for providing helpful comments and edits.

This paper, which may be revised, is available on the web site of the Federal Reserve Bank of Boston at http://www.bos.frb.org/economic/ppdp/2008/ppdp0802.htm.

The views expressed in this paper are solely those of the authors and not necessarily those of the Federal Reserve Bank of Boston or the Federal Reserve System.

This version: May 30, 2008 


\section{Overview}

The Federal Reserve Bank of Boston's research project on foreclosures began in March 2007, when the Bank's then-president, Cathy E. Minehan, asked us in the research department why the foreclosure rate in New England was rising so rapidly. To answer this question, we gathered data, starting with a list of foreclosures that had occurred in the week immediately prior to our initial discussion with Cathy. Over time, we added datasets that covered, in various ways and to varying degrees, every borrower and every mortgage issued in Massachusetts since 1987. This paper presents some of what we have learned from these data and discusses some of the issues that still puzzle us. Our results focus on Massachusetts because this is the state for which we have the most data and the most knowledge. In some cases, as we will discuss, we think the basic findings hold for the nation as a whole. In other cases, we think findings are relevant only for Massachusetts or New England.

We view this paper as a resource for policymakers. To this end, we have eschewed the use of mathematical formulas and jargon typical in scholarly economics papers. But we also hope that researchers find this paper valuable, both as a description of the strengths and weaknesses of available data, and as an outline of some basic findings about the mortgage market and the recent subprime crisis.

We distill our findings into what we think are seven basic "facts" about the foreclosure wave that started in 2006, which we list and briefly review in the first section. We then discuss some outstanding questions to which we can find no satisfactory answers.

The facts are:

1. Interest-rate resets are not the main problem in the subprime market.

2. Higher foreclosure rates stem from falling house prices.

3. Prime lenders would have rejected most of the loans originated by subprime lenders.

4. Many recent foreclosees put little money down and had lived in their homes a short time.

5. Current Massachusetts foreclosures involve a disproportionate number of multi-family dwellings.

6. Most recent foreclosures in Massachusetts involved homes that were initially purchased with prime mortgages.

7. Almost half of the residential foreclosures in Massachusetts came on subprime mortgages, including subprime refinances of prime purchase mortgages. 


\section{Seven Subprime Facts: A Brief Review}

FACT 1: InTEREST-RATE RESETS ARE NOT THE MAIN PROBLEM IN THE SUBPRIME MARKET

One of the most enduring claims about the origins of the subprime mortgage crisis centers on the resets of hybrid adjustable-rate mortgages (ARMs). The typical criticism of these mortgages is as follows: hybrid ARMs offer borrowers extremely low fixed interest rates during an initial "teaser" period, but then the rate "explodes" to something much higher a few years after origination. Lenders find such loans attractive because of the high post-reset interest rates. Borrowers find them attractive because of the low teaser rates, but later regret their decisions when they find themselves paying high interest rates and thus higher mortgage payments. Finally, the subprime mortgage crisis emerged when a large number of ARM rates reset and previously solvent borrowers found themselves facing unaffordable monthly payments. ${ }^{1}$

We will illustrate that virtually everything about the above story is wrong. Subprime teaser rates were not exceptionally low; in fact, by reasonable standards, these rates were exceptionally high. The interest-rate resets, although not trivial, were not explosive. ${ }^{2}$ The high post-reset rates were not the attraction for lenders, because most borrowers prepaid such mortgages prior to or shortly after the reset, a fact anticipated by lenders. ${ }^{3}$ And finally, loan-level data show little relationship between the timing of the resets and delinquency and foreclosure activity, even among the most recent foreclosures. ${ }^{4}$

Though we minimize the specific importance of resets to the subprime market, in some respects our conclusion is more pessimistic than press accounts that focus on resets alone. Recent declines in short-term interest rates have lowered the rates at which subprime mortgages will reset this year. In some cases, the new interest rate will be quite close to the initial rate on the subprime loan. Unfortunately, the fact that so many subprime borrowers are having problems keeping their loans current even at the lower initial rates means that problems in the subprime market are likely to continue for reasons unrelated to interest-rate resets.

\footnotetext{
${ }^{1}$ This theory has appeared innumerable times in the media. Gretchen Morgenson writes in The New York Times on April 8, 2007, "Especially ingenious - for lenders, at least - were so-called exploding A.R.M.'s that lured borrowers with unusually low teaser rates that then reset skyward two or three years later (typically pegged to the London Interbank Offered Rate, plus six percentage points)."

${ }^{2}$ See Table 3 on page 14 for a table of teaser rates and resets.

${ }^{3}$ See Figure 2 on page 16 for data on refinancing activity among subprime ARMs.

${ }^{4}$ See Figure 4 on page 19 for a graph of default probabilities among subprime adjustable-rate mortgages.
} 


\section{FACT 2: Higher FORECLOSURE RATES STEM From FALling HOUSE PRices}

If subprime resets are not the main problem with the nation's housing market today, then why are so many borrowers (both subprime and prime) losing their homes? We make the case that the proximate cause of the current explosion in foreclosures is falling house prices. Figure 5 on page 20 shows that periods of high foreclosure activity are associated with falling house prices. More formally, the econometric evidence from Gerardi, Shapiro, and Willen (2007, henceforth GSW) shows that this link is causal: falling house prices cause foreclosures. An alternative explanation of this result might be that the causality runs not from prices to foreclosures, but from foreclosures to prices. This argument rests on the idea that some other factor - resets on ARMs, perhaps - causes household-level cash-flow problems, which in turn foster foreclosures. The surge in foreclosures then dumps residential properties on the market, so house prices fall.

The experience of the Massachusetts housing market during the 2001 recession, however, shows why household-level cash-flow problems are, by themselves, unlikely to cause widespread foreclosures. The 2001 recession caused severe cash-flow problems among Massachusetts homeowners, as the state's 30-day mortgage delinquency rate rose sharply in that year. But Massachusetts house prices continued rising in 2001, which caused the foreclosure rate to decline. In fact, during this period, the state's delinquency and foreclosure rates both broke records, but these records went in opposite directions: the year 2001 saw the highest delinquency rate and the lowest foreclosure rate in our data up to that time. ${ }^{5} \mathrm{~A}$ negative relationship between house price appreciation and foreclosures is also present at the microeconomic level. The data show that among individual homeowners, borrowers who have seen the market value of their homes fall by more than 20 percent since the purchase are more than 15 times more likely to lose their homes as compared to people who have seen their property values appreciate by at least 20 percent. $^{6}$

Many people have interpreted these findings to suggest that the current foreclosure wave results from borrowers "walking away" from their homes when a situation of negative equity is reached, defined as when the outstanding mortgage balance exceeds the current market value of the house. In reality, the story is more complex. To be sure, default rates rise for borrowers with negative equity, but most borrowers with negative equity do not lose their homes to foreclosure. We argue that adverse individual financial shocks - like job loss, illness, and divorce - create household-level cash-flow problems even when the economy is doing well. For borrowers with positive equity, these adverse events lead to profitable sales or, potentially, refinances. But for borrowers with negative equity, bad financial shocks

\footnotetext{
${ }^{5}$ See Figure 6 on 21 for a graph of the delinquency rate and house-price appreciation in Massachusetts.

${ }^{6}$ See Figure 7 on 23 for a graphical display of this finding.
} 
typically presage foreclosure. Thus, many of the borrowers defaulting today are experiencing a "life event," like a job loss or divorce, that has little to do with the falling market value of their homes, but much to do with their ability to meet their monthly mortgage payments.

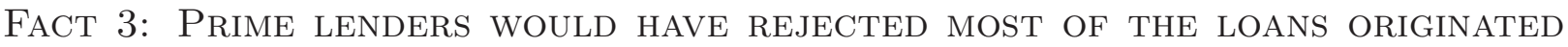
BY SUBPRIME LENDERS

Some commentators and policymakers have argued that a substantial fraction of borrowers who obtained subprime loans could have qualified for prime loans. The main evidence offered to support this view is that, as the subprime lending activity increased in the mid-2000s, an increasing fraction of subprime borrowers were not "traditional" subprime borrowers, meaning borrowers with poor credit histories. Instead, borrowing from subprime lenders grew rapidly among individuals with good credit histories. Using our data, we replicate the finding that an increasing fraction of subprime loans were made to borrowers with FICO scores above 620 , which is generally considered the cutoff point between prime and subprime borrowers. ${ }^{7}$

However, our data also show that prime lenders would probably not have given these high-score borrowers the loans that they actually obtained in the subprime market. The reason is that a low FICO score is not the only reason that a prime lender will reject a loan application. Prime lenders also frown on high loan-to-value ratios, high payment-to-income ratios, and an unwillingness to fully document income and assets. In our data, about 70 percent of subprime loans were taken out by borrowers with high FICO scores at the height of the housing boom, but less than 10 percent of these loans met all of the tests for obtaining a loan from a prime lender. ${ }^{8}$ Furthermore, under the risk-based pricing model used by most subprime lenders, borrowers who came close to qualifying for prime loans were able to obtain near-prime interest rates as well.

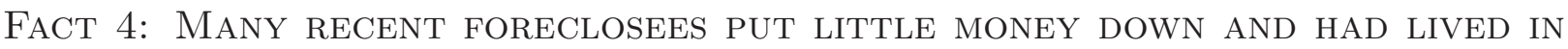
THEIR HOMES A SHORT TIME.

In 2007, 40 percent of Massachusetts residents who lost their homes to foreclosure had put no money down when they bought their homes. More than half made less than a 5 percent downpayment. Furthermore, almost half of recent Massachusetts foreclosees had owned their house for less than three years, a period which encompasses the entire foreclosure

\footnotetext{
${ }^{7}$ FICO is the acronym for Fair Isaac \& Co., which developed a widely used score designed to evaluate creditworthiness. See the top line of the upper left panel of Figure 9 on page 30 for data on the share of high-FICO borrowers in the subprime pool.

${ }^{8}$ See the bottom line of the upper left panel of Figure 9 on page 30.
} 
process. ${ }^{9}$ Both the lack of initial equity in the housing investment and the short average tenure for the typical foreclosee represent a change from previous Massachusetts foreclosure waves. In 1991 and 1992, when foreclosures last peaked in the state, the typical foreclosee had invested a substantial amount in the original downpayment and had lived in the house for much longer.

FaCt 5: Current Massachusetts foreclosures involve a Disproportionate NUMBER OF MULTI-FAMILY DWELLINGS

Multi-family dwellings, meaning properties containing between two and four separate units, account for slightly more than 10 percent of residential purchases in Massachusetts, but they account for almost 30 percent of current foreclosures. Because most of the units in multi-family dwellings are rented, and because lenders typically evict renters when they foreclose, the prevalence of multi-family foreclosures means that the pool of Massachusetts families directly affected by the current foreclosure wave significantly exceeds the number of foreclosures.

The prevalence of multi-family foreclosures provides another contrast between the current foreclosure wave in Massachusetts and the earlier one. The early 1990s foreclosure episode followed a burst of residential construction in Massachusetts, in which new condominiums were often used as investment vehicles. When this building boom ended and house prices fell, many of these investment properties ended up in foreclosure. By contrast, residential construction was much more subdued in Massachusetts during the early 2000s boom. The condominium share of foreclosures has been replaced to some extent by foreclosures of multi-family properties, many of which are probably also attributable to investments gone bad. Unfortunately, the negative external effects from multi-family foreclosures are generally more serious than from condominium foreclosures, due to the eviction of renters living in the multi-family dwellings.

FaCt 6: Most ReCEnt foreclosures in Massachusetts involved homes that WERE INITIALLY PURCHASED WITH PRIME MORTGAGES

Because of their high sensitivity to house prices, homes purchased with subprime mortgages are experiencing higher default rates than homes purchased with prime mortgages. Yet, by our measures, subprime purchases accounted for less than 15 percent of all residential purchases in Massachusetts, even at the peak of subprime purchases in 2005. This small share means that even though subprime purchasers are more likely to default, these

\footnotetext{
${ }^{9}$ From first delinquency to the lender's repossession of the house, the foreclosure process in Massachusetts can easily extend for more than a year.
} 
purchases account for only about 30 percent of all current foreclosures, with prime purchases making up the other 70 percent. Looking deeper into the pool of prime-purchase foreclosures, we see that, as expected, borrowers who purchased their homes at the peak of the recent housing boom are more likely to default, because their owners are less likely to have accumulated positive equity in their homes. However, most homes in Massachusetts were purchased before the early 2000s boom, so homes purchased before 1999 account for 42.6 percent of the prime-purchase foreclosures in 2006 and 2007.

Fact 7: Almost half of the Residential foreclosures in Massachusetts Came ON SUBPRIME MORTGAGES, INCLUDING SUBPRIME REFINANCES OF PRIME PURCHASE MORTGAGES

The presence of homes purchased before 1999 in the current foreclosure pool raises an interesting question. Since 1999, according to our measures, the cumulative increase in Massachusetts house prices has been more than 60 percent. How could a home that was purchased when house prices were so much lower be lost to foreclosure today? The most likely reason is that the owner withdrew and spent some of the accumulated housing equity in a cash-out refinance. Data limitations prevent us from measuring the precise amount of equity removed from foreclosed homes. But we are able to show that refinancing activity is higher for foreclosed homes, especially among cohorts of homes that were purchased before the recent boom in housing prices. The intensity of this refinancing activity brings us back to the important role that subprime lending has played in the current foreclosure wave. As noted above, 70 percent of the homes lost to foreclosure in 2006 and 2007 were purchased with prime loans, leaving the subprime share at 30 percent. But a little less than half (45.2 percent) of all defaulted mortgages in 2006 and 2007 were subprime mortgages. The latter subprime share is higher than 30 percent because many people who purchased homes with prime mortgages refinanced into subprime mortgages and then defaulted.

\section{Some outstanding questions}

We conclude by discussing outstanding questions relevant to policymakers as they address the current housing crisis:

- Were adjustable-rate subprime mortgages good deals for subprime borrowers?

- How many subprime borrowers were inappropriately "steered" into their mortgages?

- Did subprime lending cause the house-price boom of the early 2000s?

- Did subprime lending increase the homeownership rate?

Each of these questions is important for policymakers tasked with addressing the current 
subprime crisis and ensuring that this type of crisis does not happen again. Unfortunately, for various reasons, each question is also difficult to answer with currently available data. Our concluding section discusses why these questions are hard to answer and what type of data would be needed to make headway on them. In an appendix, we present some initial work designed to address the first question, which relates to the pricing and performance of subprime ARMs. Specifically, Appendix A compares the interest rates paid on subprime ARMs with those of subprime fixed-rate mortgages (FRMs). This appendix also compares the default probabilities of ARMs versus FRMs as house prices fall. The data show that subprime ARMs default more quickly than FRMs as house prices decline. Additionally, ARMs also have initial interest rates that are strikingly close to interest rates on FRMs. ${ }^{10}$ Unfortunately, it is hard to know whether these patterns are generated by intrinsic differences in the structure of ARMs and FRMs, or instead by differences in the types of persons who are likely to choose ARMs rather than FRMs.

The remainder of the paper is organized as follows. Section 2 describes the two main datasets we have used in our analysis. Section 3 outlines our findings, and Section 4 concludes with the outstanding questions.

\section{Background}

\subsection{The Warren Group's Registry of Deeds Data}

The most fundamental dataset in our research was supplied by The Warren Group, a private Boston firm that has been tracking real estate transactions in New England for more than a century. ${ }^{11}$ The Warren Group dataset is a standardized, electronic version of publicly available real estate transaction records filed at Massachusetts Registry of Deeds offices during the past twenty years. The dataset includes the universe of purchase mortgages, refinance mortgages, home equity loans, and purchase deeds transacted in Massachusetts from January 1987 through March 2008. Foreclosure deeds are available starting in 1989. So, for every house purchased in the state during the sample period, we know the location and price of the house, the size of all mortgages associated with the sale, ${ }^{12}$ and the identity of the mortgage lender, among other variables. From these data, we can construct a variety

\footnotetext{
${ }^{10}$ One would expect that initial interest rates on subprime ARMs would be much lower than rates on FRMs, because ARM borrowers should be compensated for the possibility that their interest rates will rise in the future.

${ }^{11}$ Among other things, the Warren Group publishes the newspaper Banker and Tradesman, which provides up-to-date information on housing-market trends and foreclosure statistics for the New England area. The company began collecting data and publishing Banker and Tradesman in 1872 .

${ }^{12}$ Specifically, we see second mortgages ("piggybacks") as well any other mortgage secured by the home.
} 
of useful statistics. For example, because we know the loan amounts for all mortgages associated with a house purchase, as well the sale price, we can calculate the combined loan-to-value ratio (LTV) for each home purchase in the data.

Figure 1: Sales and Foreclosures in Massachusetts, 1990-2007

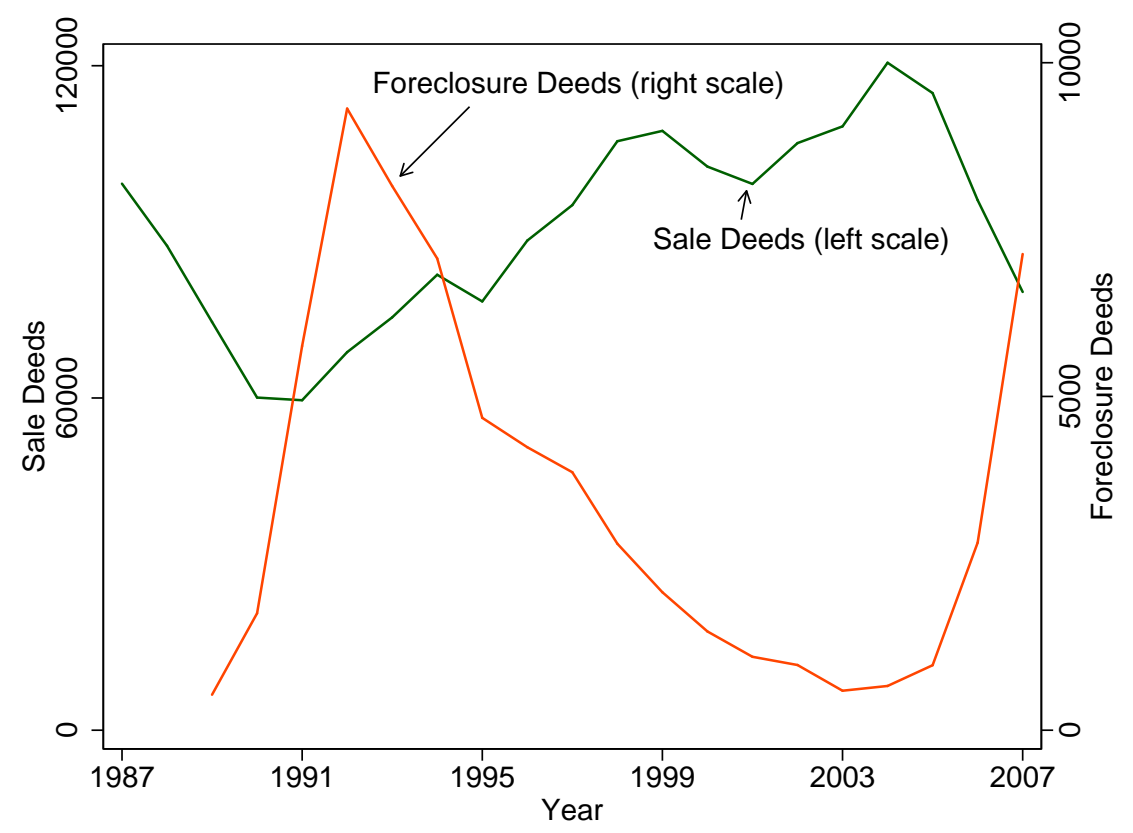

Figure 1 presents Massachusetts sales and foreclosures by year obtained from the Warren Group dataset. The graph clearly illustrates the state's two foreclosure waves during the past two decades. The first of these occurred in the early 1990s, when the combination of a severe recession and a significant downturn in the housing market resulted in a dramatic increase in foreclosures. In 2006 and 2007, we see mounting evidence of the state's current foreclosure wave.

A crucial benefit of the Warren Group dataset is that it includes a special identifier that allows us to link mortgages taken out by a single homeowner during the entire time he occupied a given house, a period that we term an ownership experience. By constructing ownership experiences, we can carry variables generated at the time of purchase through all of the periods that the owner lives in the home, even if he refinances out of the initial purchase mortgage. An example of such a variable is the homeowner's initial LTV ratio, which correlates with eventual foreclosure probabilities. Table 1 presents LTV ratios for the complete sample of Massachusetts ownership experiences, as well as for those ownerships that end in foreclosure. The first lesson from the table is that average purchase LTVs have risen over time, from 79 percent in 1990 to 84 percent in 2007. (The increase is even greater 
Table 1: Initial Loan-to-Value Ratios, by Year of Purchase

\begin{tabular}{l|rcc|rcc}
\hline \hline & \multicolumn{3}{|c|}{ All ownerships } & \multicolumn{3}{c}{ Ownerships that default } \\
\cline { 2 - 7 } & \# & mean & median & \# & mean & median \\
\hline \hline 1990 & 44,545 & 0.79 & 0.80 & 2,495 & 0.87 & 0.90 \\
1991 & 45,436 & 0.80 & 0.80 & 1,218 & 0.90 & 0.95 \\
1992 & 53,807 & 0.81 & 0.80 & 913 & 0.91 & 0.95 \\
1993 & 61,004 & 0.82 & 0.85 & 906 & 0.92 & 0.95 \\
1994 & 66,568 & 0.83 & 0.88 & 931 & 0.92 & 0.95 \\
1995 & 60,762 & 0.83 & 0.88 & 850 & 0.94 & 0.97 \\
1996 & 69,718 & 0.83 & 0.88 & 831 & 0.94 & 0.98 \\
1997 & 74,350 & 0.83 & 0.86 & 822 & 0.93 & 0.97 \\
1998 & 85,947 & 0.83 & 0.85 & 715 & 0.92 & 0.95 \\
1999 & 86,895 & 0.83 & 0.85 & 769 & 0.92 & 0.95 \\
2000 & 78,045 & 0.82 & 0.85 & 776 & 0.92 & 0.95 \\
2001 & 77,645 & 0.82 & 0.87 & 696 & 0.92 & 0.95 \\
2002 & 81,337 & 0.82 & 0.85 & 822 & 0.92 & 0.95 \\
2003 & 86,966 & 0.82 & 0.85 & 1,072 & 0.92 & 0.95 \\
2004 & 95,890 & 0.82 & 0.87 & 1,875 & 0.94 & 0.98 \\
2005 & 94,539 & 0.83 & 0.90 & 2,291 & 0.95 & 1.00 \\
2006 & 79,142 & 0.84 & 0.90 & 1,291 & 0.96 & 1.00 \\
2007 & 67,127 & 0.84 & 0.90 & 59 & 0.94 & 1.00 \\
\hline \hline
\end{tabular}

if one tracks median LTV rather than mean LTV.) A second takeaway from Table 1 is the well-known regularity that high-LTV ownership experiences are more likely to end in default. Average LTVs among defaulting ownership experiences are generally 8-12 percentage points higher than the LTV for the typical ownership experience.

Additionally, because the Warren Group data track individual houses across different purchases, we can use the data to construct a statewide repeat-sales index. The repeat-sales method, originally set forth in Case and Shiller (1987), aggregates price changes for individual homes between sales. Because a repeat-sales index is built up from price comparisons of the same houses at different points in time, the index should not be contaminated by changes in the underlying quality of the housing stock. ${ }^{13}$ The repeat-sales method is also used by the Office of Federal Housing Enterprise Oversight (OFHEO) to generate price indexes for the nation and for individual states and metro areas. However, data for the OFHEO indexes are limited to purchases financed with agency-conforming mortgages, while our index

\footnotetext{
${ }^{13}$ One drawback to the repeat sales method is that it is impossible to know which houses have undergone major renovations in the Warren Group data, and which therefore should be excluded from the repeat sales calculations. We excluded any home that had risen in value by more than 50 percent for repeat sales within one year, and by more than 100 percent for repeat sales within three years, figuring that such a large price increase could only be explained by a renovation. In practice, the precise cutoff that we used to exclude renovations made little difference to our final results. See Appendix A of GSW (2007) for details.
} 
includes all home purchases in Massachusetts. ${ }^{14}$ Because agency-conforming mortgages are generally prime mortgages, and because our paper focuses on subprime lending, the use of a broader price index is important. In Appendix B, we compare our price index with OFHEO's, as well as with the S\&P/Case-Shiller price index for Boston. The latter includes homes purchased with both conforming and non-conforming mortgages, but only for the Boston area. In general, all three indexes are in close agreement in the periods where they overlap. However, the two indexes that include non-conforming mortgages (our statewide index and the $\mathrm{S} \& \mathrm{P} /$ Case-Shiller index for Boston) show larger price declines during the housing downturns of the early 1990s and the mid-to-late 2000s.

The wide coverage and breadth of variables in the Warren Group dataset make it uniquely useful for housing research. However, the dataset does have some important shortcomings. The most significant is a lack of information on interest rates. Massachusetts law does not require interest rates on fixed-rate loans to be recorded at deed registries. For ARMs, interest rates are included in special riders to the main transaction records, but the Warren Group has not yet transcribed this information electronically (with some exceptions discussed below). Another disadvantage of the Warren Group dataset is that it does not tell us when any particular mortgage is paid off, or discharged. The lack of information on discharges prevents us from calculating the amount of cash-out refinancing at various points. ${ }^{15}$ Finally, the Warren Group dataset does not include any demographic information about borrowers, such as income, race, or previous credit history.

\subsection{LoanPerformance Data}

Most of our information on interest rates and other detailed mortgage characteristics comes from FirstAmerican LoanPerformance (LP). This firm collects information on individual loans that have been packaged into non-agency, mortgage-backed securities (MBS) and sold to investors on the secondary mortgage market. We refer to two separate LP

\footnotetext{
${ }^{14} \mathrm{An}$ agency-conforming mortgage is one that conforms to limits set for the two major governmentsponsored agencies in the secondary mortgage market, the Federal Home Loan Mortgage Corporation (Freddie Mac) and the Federal National Mortgage Association (Fannie Mae). Agency-conforming mortgages are generally prime mortgages that do not exceed a certain limit, which until recently was $\$ 417,000$ for single-family homes. Recently, Congress enacted a temporary raise of this limit to $\$ 729,750$ in certain high-cost areas.

${ }^{15}$ Obviously, if a new mortgage is used to pay off an old one, then the amount of cash left over for the homeowner will be much smaller than if the old mortgage remains on the books. Therefore, calculating the amount of equity taken out of the house with any degree of accuracy requires us to know when and if a particular mortgage is discharged. Discharges are officially registered at Massachusetts deeds offices and we are currently looking into ways of adding them to the Warren Group data. An obvious case where discharges can be inferred with the data we do have is when a house is sold, in which case all outstanding mortgages are discharged.
} 
datasets in our research. The first is a loan-level dataset that the Boston Fed purchased from LP in mid-2007. This dataset covers Massachusetts, Connecticut, and Rhode Island from 1992 through August 2007. ${ }^{16}$ Elsewhere in this paper, we will refer to summary statistics generated by a nationwide LP dataset that was purchased by the Board of Governors of the Federal Reserve System in Washington, D.C., and used by research economists there.

The major strength of the LP dataset is its extensive loan-level information on interest rates and other lending terms. It also contains information regarding the type of MBS each loan was packaged into-subprime, Alt-A, or prime. ${ }^{17}$ In addition, the LP dataset also includes information on borrowers. For approximately 97 percent of the loans in our sample we know the borrower's credit score. For 60 percent of the loans we know the debt-to-income ratio (DTI), which is simply the borrower's monthly debt payment divided by his monthly income, ${ }^{18}$ while for virtually every loan in our sample we know the combined LTV ratio implied by the size of the loan and the value of the house. ${ }^{19}$ A major shortcoming of the LP dataset is the inability to create complete ownership experiences by matching loans made to the same borrower on the same house. Also, the LP dataset has only limited information on borrowers. Like the Warren Group dataset, the LP dataset does not include demographic information such as race, education, or gender. ${ }^{20}$

\subsection{Defining the "Subprime" Market}

A paper discussing facts about the subprime market obviously needs a definition of "subprime" lending, but there is no single way to define the subprime market. One description could be based on the characteristics of borrowers. A subprime borrower could be some-

\footnotetext{
${ }^{16}$ To be specific, 1992 was the first year in which a pool of securitized mortgages was included in the LoanPerformance dataset. However, the mortgage pools sometimes include mortgages that were originated well before the securitization process was initiated. Thus, there are mortgages in the dataset that were originated before 1992, but because of sample selection issues, we do not use any information from those mortgages.

${ }^{17}$ The Alt-A classification is for loans whose riskiness falls between that of the subprime and prime classifications. Because the LP data cover only non-agency securities, the prime loans included in the LP data are typically jumbo loans. Jumbo loans exceed the federally mandated limit for securitization by Freddie Mac or Fannie Mae.

${ }^{18}$ This calculation includes the amount of the monthly mortgage payment, as well as other types of debt, such as credit card debt, car loans, education loans, and medical loans. In the housing-finance literature, this debt-to-income ratio is typically referred to as the "back-end" debt-to-income ratio. The "front-end" ratio involves only the home mortgage debt itself.

${ }^{19}$ The LTV ratio in the LoanPerformance data includes second mortgages, but (unlike the Warren Group dataset) LP does not include home-equity loans or home equity lines of credit. For purchases, the value of the house is assumed to be the purchase price, while for refinances, the appraised value of the house is used.

${ }^{20}$ The LP dataset does contain zip codes, however, so demographic information can be matched to loans at the zip-code level. The same is true of the Warren Group data.
} 
one who has missed a mortgage payment during the past year or two, who has filed for bankruptcy in the past few years, or who has a low FICO score for other reasons. However, as noted above, many borrowers with good credit scores also made use of the subprime market, especially at the height of the housing boom. Alternatively, a subprime definition could be based on lenders. Many lenders typically, but not exclusively, originated loans to subprime borrowers, generally with high fees and interest rates. Yet these same lenders also made loans to prime borrowers. ${ }^{21}$ Finally, we can construct a subprime designation using information on characteristics of the loans. For example, we could define a subprime loan to be a mortgage that was packaged into a subprime MBS.

The availability of different information in our two main datasets leads to different definitions of the subprime market. The Warren Group dataset does not contain mortgage interest rates or credit scores, so we use the identity of the lender to characterize individual mortgages as subprime or prime. Our list of subprime lenders comes from the Department of Housing and Urban Development (HUD), which has maintained a list of predominantly subprime lenders since 1993. HUD bases this list on characteristics of lenders' business models that are generally associated with subprime lending. ${ }^{22}$ By standardizing this list across years and matching it to the lender variable in the Warren Group dataset, we can designate loans in this dataset as subprime or prime. A drawback of this approach is that subprime lenders sometimes make prime loans. To get a sense of the misclassification that the use of the HUD list is likely to generate, we checked our subprime classification against interest rates in a small subsample of ARMs that the Warren Group had recorded electronically. The results were gratifying. Of the mortgages in the Warren Group data that were identified as subprime from the HUD list, and for which interest rate information is available, approximately 93 percent had an initial rate of at least 200 basis points ${ }^{23}$ above an equivalent prime mortgage rate, or had an associated margin of at least 350 basis points above the typical benchmark interest rate used for determining subprime rates. ${ }^{24}$

\footnotetext{
${ }^{21}$ An example of such a firm is Countrywide.

${ }^{22}$ Specifically, a lender makes the HUD list if most of its business is in refinance rather than purchase loans, and if the lender does not sell a significant portion of its portfolio to the two government-sponsored housing agencies (Fannie Mae and Freddie Mac). Recently HUD has checked its subprime list against the designation of "high-cost" loans in a dataset generated by the Home Mortgage Disclosure Act, which began tracking high-cost loans in 2004. This exercise has found that the HUD lender list is in general agreement with the HMDA high-cost variable. The HUD list and supporting documentation is available at http://www.huduser.org/datasets/manu.html.

${ }^{23} \mathrm{~A}$ basis point is one one-hundredth of a percentage point, so 200 basis points equals 2 percentage points.

${ }^{24}$ More extensive robustness checks for the subprime classification in the Warren Group dataset are found in Appendix B of GSW (2007). A "margin" on a subprime adjustable-rate mortgage is the constant difference between a benchmark interest rate (typically 6-month LIBOR) and the "fully indexed" interest rate, which obtains when the subprime ARM is reset. We discuss the institutional details involved in the pricing of subprime adjustable-rate mortgages more extensively below.
} 
Table 2: Top 10 Subprime Lenders in Massachusetts, 1993-2007

\begin{tabular}{l|r|r|c}
\hline \hline & \# loans & $\begin{array}{r}\text { \% of subprime } \\
\text { purchase mortgages }\end{array}$ & status \\
\hline Option One Mtg. Corp. & 11,243 & 18.6 & shutdown \\
New Century Financial Corp. & 5,951 & 9.9 & shutdown \\
Fremont Investment \& Loan & 5,550 & 9.2 & shutdown \\
Argent Mtg. Co. & 3,599 & 6.0 & shutdown \\
Summit Mtg. Co. & 3,067 & 5.1 & shutdown \\
Mortgage Lender Net & 2,798 & 4.6 & shutdown \\
Long Beach Mtg. Co. & 2,520 & 4.2 & shutdown \\
WMC Mtg. Corp. & 2,316 & 3.8 & shutdown \\
Accredited Home Lenders & 2,174 & 3.6 & shutdown \\
First Franklin Financial & 1,896 & 3.1 & shutdown \\
\hline Total & 41,114 & 68.1 & - \\
\hline \hline
\end{tabular}

Table 2 lists the top 10 originators of subprime loans in the Warren Group dataset from 1993 to 2007, according to the HUD list. The bottom row of this table shows that these lenders made slightly more than two-thirds of all subprime loans in Massachusetts during this period. Yet the decline in subprime lending since 2006 has hit this group hard. None of these lenders are operating in the state today.

In the LP data, creating the subprime loan designation is conceptually easier. Subprime mortgages are those that were securitized into a subprime MBS (as opposed to prime or Alt-A). No restriction is made on the FICO score of the borrower, and, as we will see, many borrowers who took out subprime loans in the LP dataset had relatively good credit scores. Also note that, unlike the Warren Group dataset, the subprime definition is not based on the originator of the mortgage, but rather the type of security into which the mortgage was grouped for the secondary market.

\section{Seven Subprime Facts}

\subsection{Fact 1: Interest-rate resets are not the main problem in the subprime market}

Many of the policy proposals that have been advanced to address the housing crisis involve interest-rate resets among subprime ARMs. ${ }^{25}$ In this section, we discuss subprime

\footnotetext{
${ }^{25}$ In December 2007, the White House announced the voluntary Hope Now initiative, in which lenders agreed to suspend interest-rate resets for five years for borrowers who could afford their mortgages only
} 
resets and show that they were not the main cause of the subprime crisis. Thus, policies that address resets are unlikely to reduce the severity of the foreclosure crisis. We divide our discussion into two sections. First, we show that the role of resets in the subprime "business model" is widely misunderstood. We then show that there is little relationship between the timing of interest-rate resets and the timing of defaults.

\subsubsection{The subprime business model}

Proponents of the centrality of resets in the current crisis based their view on the following logic. Subprime hybrid ARMs offer borrowers extremely low "teaser" rates for some initial period (usually two or three years) but then these mortgages "explode" to high rates thereafter. Lenders find such loans attractive because of the high post-reset interest rates. Borrowers find them attractive because of the teaser, but then regret their decisions when they find themselves paying high interest rates. Is this an accurate description of the subprime lending model? No.

Table 3: Interest Rates for Subprime 2/28 Mortgages, by Year of Origination

\begin{tabular}{|c|c|c|c|c|}
\hline $\begin{array}{l}\text { Year of } \\
\text { Origination }\end{array}$ & $\begin{array}{c}\text { Initial } \\
\text { (pre-reset) } \\
\text { interest rate }\end{array}$ & $\begin{array}{l}\text { 1-year } \\
\text { prime ARM } \\
\text { rate }\end{array}$ & $\begin{array}{c}\text { Margin of } \\
\text { fully-indexed } \\
\text { (post-reset) rate } \\
\text { over benchmark rate }\end{array}$ & $\begin{array}{l}\text { Fully indexed } \\
\text { interest rate }\end{array}$ \\
\hline 2004 & 7.3 & 3.9 & 6.1 & 11.5 \\
\hline 2005 & 7.5 & 4.5 & 5.9 & 10.5 \\
\hline 2006 & 8.5 & 5.5 & 6.1 & 9.1 \\
\hline 2007 & 8.6 & 5.7 & 6.1 & 9.1 \\
\hline
\end{tabular}

Note: The 2006 and 2007 cohorts of mortgages reset in 2008 and 2009. For these mortgages, the 6-month LIBOR two years after origination is assumed to be 3.0 percent (the April 2008 value) to allow comparison with other cohorts.

First, there was never something like a low "teaser" rate on the typical subprime ARM. Table 3 presents summary statistics from the Board of Governors's LP dataset on " $2 / 28$ " mortgages originated from 2004 to 2007. This type of 30-year mortgage is by far the most common type of subprime ARM. The " 2 " in the $2 / 28$ designation refers to the fact that the interest rate is fixed for the loan's first two years. For the remaining 28 years of the loan, the interest rate adjusts every six months until the mortgage is paid off. Almost all 2/28s were

at their initial interest rates. Resets are also a component of the government's new FHASecure program, announced in August 2007. This program initially allowed borrowers who were delinquent on their mortgages to qualify for new FHA loans, but only if these delinquencies resulted from previous interest-rate resets. In April 2008, the program was extended to borrowers who had missed a limited number of payments either before or after their resets. 
fully-amortized, meaning that the borrower repays some of the principal with every monthly payment. Table 3 shows that the initial interest rate for subprime $2 / 28$ s ranged from 7.3 percent in 2004 to 8.6 percent in 2007. These initial rates are not low; on the contrary, they are quite high. As the table shows, 2/28 borrowers paid rates that were about three full percentage points higher than rates on the closest prime equivalent, a one-year prime ARM. In short, subprime lenders did not need to wait until the resets occurred in order to profit from these loans.

Second, the interest-rate adjustments at reset, while not trivial, were not "explosive." The "fully indexed" rate on a subprime 2/28 mortgage - the rate paid after the initial interest rate expired - typically equaled a benchmark rate plus a fixed margin. Most often, the benchmark interest rate was the 6-month London Interbank Offered Rate (LIBOR), and the margin was about 6 percentage points. Table 3 illustrates the calculation, showing both the average margin and the average fully indexed rates. When the 2004 cohort of mortgages reset in 2006, the 6-month LIBOR was around 5 percent, so a margin of about 6 percentage points generated fully indexed rates that averaged 11.3 percent. Similar numbers hold for the 2005 loans, which reset in 2007.

A comparison of the first and last columns of Table 3 shows that the the fully indexed interest rates were about three to four percentage points higher than initial rates for mortgages originated in 2004 and 2005. This would lead to a monthly payment increase, or "payment shock," of about 25 percent. While sizable, this payment shock is small compared to, say, payment shocks in the credit card market, where interest rates can easily increase by a factor of five when teaser rates expire. In addition, a simple comparison of pre- and post-reset interest rates on 2/28 mortgages typically overstates the payment shocks experienced by people who bought homes with subprime mortgages. During the height of the housing boom, many subprime purchasers also used second mortgages ("piggybacks") when they bought their homes, because they did not make downpayments of at least 20 percent. These second mortgages had high interest rates and short amortization schedules, so they accounted for a disproportionate share of a borrower's monthly house payment. Moreover, these mortgages were almost always fixed-rate loans, so they were not affected when the interest rate adjusted on the main subprime loan. The presence of second mortgages therefore limited the percentage increase in a borrower's house payment that was caused by the interest rate reset of the main 2/28 mortgage. Specifically, a reset on a 2/28 mortgage only affected about 60 percent of the typical borrower's monthly payment. ${ }^{26}$

\footnotetext{
${ }^{26}$ Consider a borrower with a $\$ 100,000$ 30-year first mortgage with an initial rate of 8.5 percent and a $\$ 25,000$ 10-year second mortgage with a contract rate of 12 percent. The initial payment on the first mortgage is $\$ 776$ and on the second is $\$ 358$, making the pre-reset payment $\$ 1134$ a month. At reset, assume that the rate on the first mortgage jumps to 11 percent, so the payment on the first mortgage jumps by 22
} 
Figure 2: Prepayment Probabilities for Subprime 2/28 ARMs, by Year of Origination

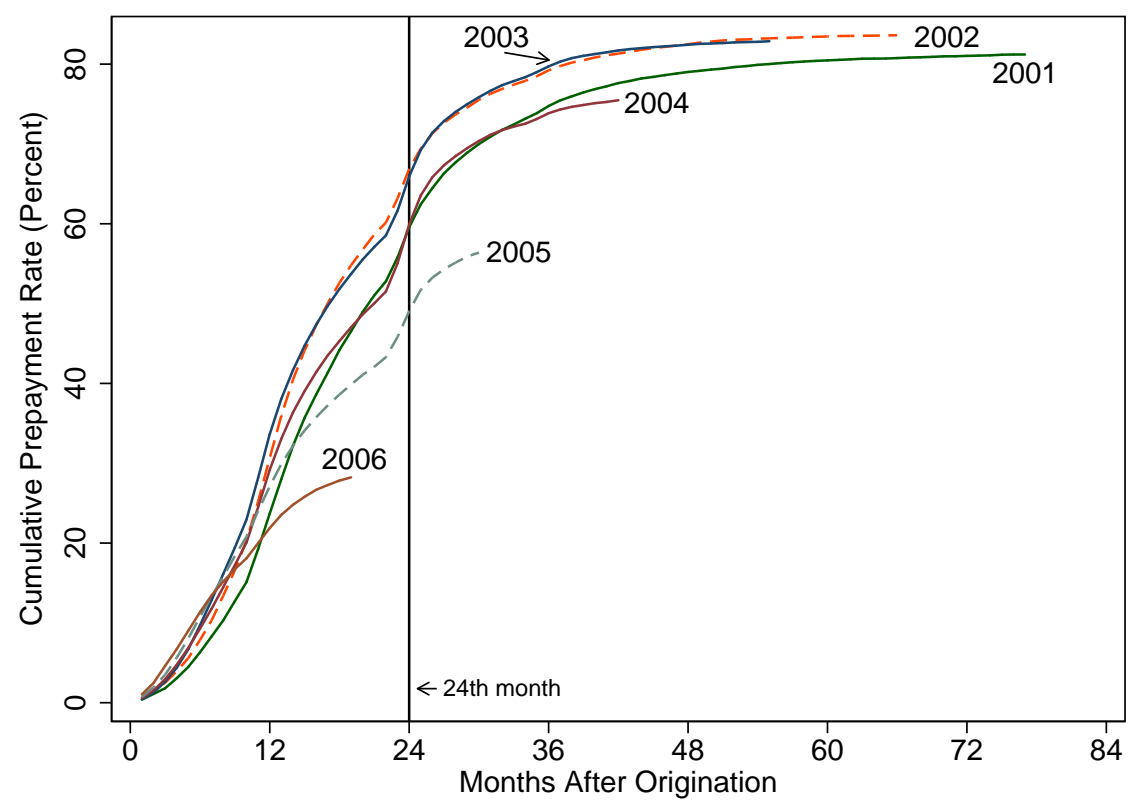

Finally, subprime lenders anticipated that most borrowers would refinance their mortgages before or shortly after their interest-rate resets. Figure 2 illustrates this point by graphing cumulative prepayment probabilities for subprime $2 / 28 \mathrm{~s}$, generated from the Boston Fed's LP dataset. Each line in this figure corresponds to a single-year cohort of loans. The 24 th month (when resets occurred) is denoted with a vertical line. The graph shows that for most yearly cohorts, a large fraction of these subprime loans - typically in excess of 70 percent-had been repaid by the 24 th month or shortly thereafter. ${ }^{27}$

Early refinancing becomes less prevalent as we move to the 2005 and 2006 cohorts. For 2005 cohorts, less than 60 percent had been discharged by the reset date. Similarly, less than one-third of the 2006 loans had been refinanced by the end of 18 months; the comparable percentage for the earlier cohorts often exceeds 40 percent. Why is refinancing activity slowing? Declines in house prices have made many houses worth less than their outstanding mortgage balances. Lenders are understandably nervous about refinancing mortgages under these circumstances. It is therefore likely that in the future, more subprime borrowers will

percent, to $\$ 952$. Because the payment on the second lien stays the same (at $\$ 358$ ), the overall payment only rises to $\$ 1,310$, or 15 percent.

${ }^{27}$ Technically, the graph displays prepayment, or "discharge" probabilities, and discharges could occur through either refinances or sales. The fact that most discharges occurred before or shortly after the 24th month strongly suggests refinancing, however. 
hit their resets and be forced to pay fully indexed rates.

While any increase in interest rates is bad news for borrowers, there is some cause for optimism regarding the effect of future resets on today's subprime borrowers. The first is that the short-term interest rates on which post-reset rates are based have recently declined, from 5.25 percent in early 2007 to less than 3 percent today. With margins of around 6 percentage points, fully indexed rates should therefore reset to around 9 percent in mid2008. This rate is quite close to the initial rate of about 8.5 percent relevant for subprime 2/28's originated in 2006 and 2007. ${ }^{28}$ Secondly, new policy initiatives will also help mitigate the effect of resets, by extending initial interest rates, or by allowing borrowers to refinance into FHA loans.

\subsubsection{Resets and foreclosures}

On balance, however, we believe that subprime mortgages will continue to experience high default and delinquency rates in 2008, because problems in the subprime market are much broader than the problem of resetting interest rates. A very simple way to see this is to note that the performance of fixed-rate subprime mortgages is also deteriorating. Figure 3 presents delinquency rates rates for subprime ARMs and FRMs in the United States, as measured by the Mortgage Bankers Association. Until mid-2007, delinquency rates for FRMs had not risen as much as those for ARMs. A common (but incorrect ${ }^{29}$ ) reading of this pattern was that subprime FRMs were doing fine and the interest-rate resets of subprime ARMs were causing all the trouble. In any case, past-due rates for FRMs have also started rising, indicating that the problem is broader than resets alone.

An even more persuasive argument against a reset-based view of subprime problems comes from noting that subprime borrowers typically fall behind on their mortgage payments before their resets occur. Figure 4 displays default probabilities for three cohorts of the subprime 2/28s from the Boston Fed's LP dataset. ${ }^{30}$ Each line in the graph corresponds to the default probability for a particular yearly cohort of loans. Default probabilities typically

\footnotetext{
${ }^{28}$ The bottom two rows of Table 3 assume that the short-term interest rates remain where they are now for the rest of 2008 and 2009. This is done to allow comparisons in post-reset interest rates across different yearly cohorts.

${ }^{29}$ The series graphed in Figure 3 are past-due rates, so they can change either because of a change in the number of past-due loans (the numerator of the past-due rate) or because a change in the number of outstanding loans (the denominator of the rate). A large number of subprime FRMs became delinquent before mid-2007, but this increase did not show up in the FRM past-due rate because of a coincident increase in the number of outstanding FRM loans. Because both the numerator and the denominator of the FRM past-due rate were rising at the same time, problems among subprime FRMs were not apparent in simple plots of the past-due rate. Given the increase in the FRM past-due rate since mid-2007, however, this is a moot point, so we do not elaborate on it further.

${ }^{30}$ Recall that this is a loan-level dataset covering only Massachusetts, Rhode Island, and Connecticut.
} 
Figure 3: Past Due Rates for Subprime Loans in the United States, 2005:q1-2007:q4

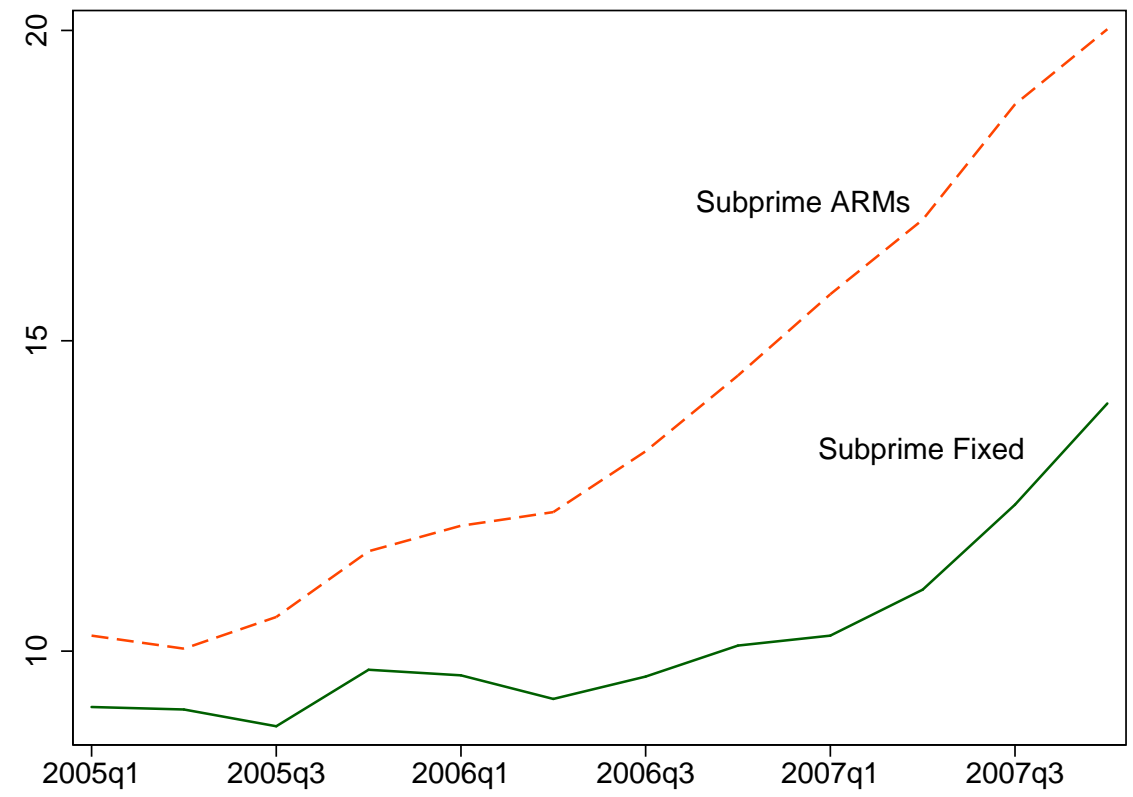

rise rapidly until the loans are about 12 months old, then decline gradually thereafter. If mortgage resets were a direct cause of foreclosure - or at least an important precipitating factor - then we would expect to see spikes in default rates at or shortly after 24 months. Yet for the two cohorts originated more than two years ago (2002 and 2005), no such spikes appear. Indeed, if a vertical line were not placed on the figure at 24 months, it would be difficult to notice anything special about this month. The most salient feature of Figure 4 is the large increase in default probabilities for the later cohorts that took place before the reset occurred. For the 2006 cohort, default probabilities are about four times higher than the 2002 cohort, even though the 2006 loans had not yet reset at the time that the figure was created. The increase in defaults for the 2005 cohort is also substantial in its pre-reset period.

One potential explanation for high pre-reset defaults among recent cohorts is that borrowers know that the loans will reset at higher rates later on. If the fully indexed monthly mortgage rates that these borrowers will eventually face are higher than they can afford, then they may simply default immediately. When resets actually occur, there is no discernable spike in foreclosures, because all of the distressed borrowers that would have defaulted at the reset date have already done so.

We take a different view of the situation. Below, we argue that the main problem with the subprime mortgage market today is not that lower house prices are preventing borrowers 
Figure 4: Default Probabilities for Subprime 2/28 ARMs, by Year of Origination

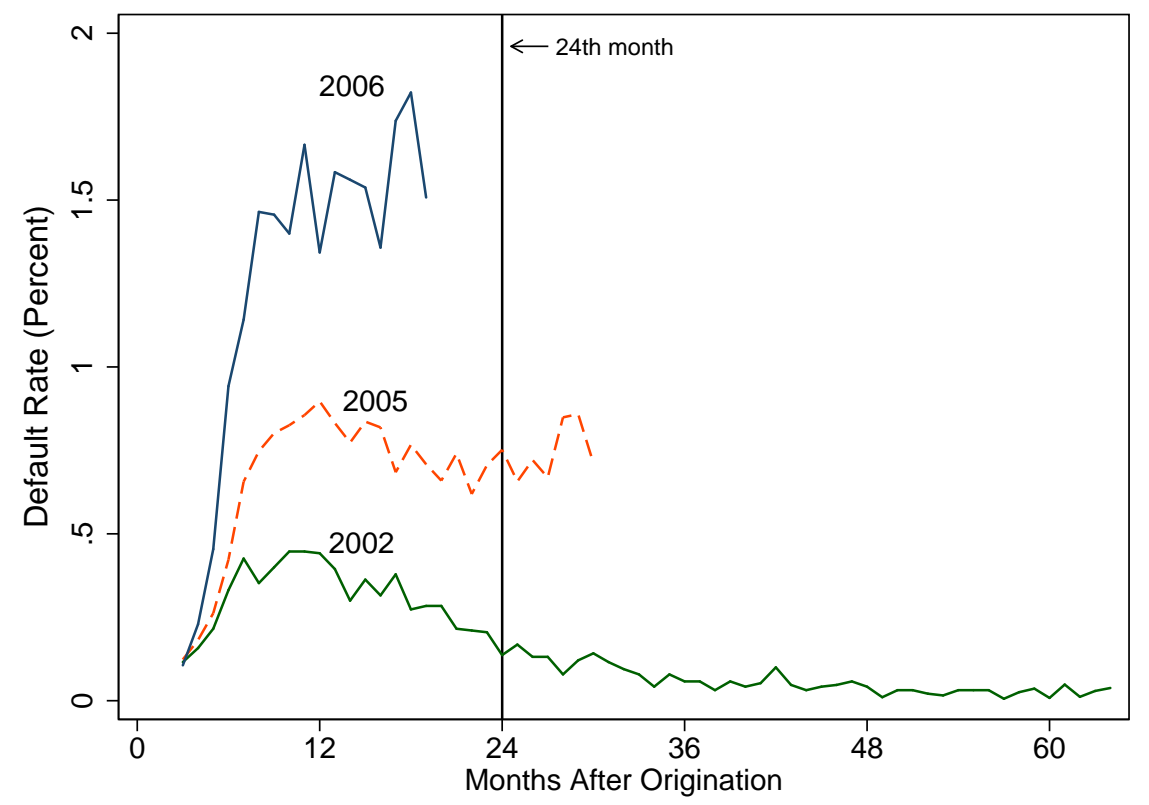

from refinancing in order to avoid their resets. Rather, the problem is that lower house prices are preventing subprime refinances for any reason. There are many circumstances under which subprime borrowers would want to refinance their loans apart from resetavoidance. Specifically, borrowers often experience temporary interruptions to their incomes (or increases in their expenses) that prevent them from making timely mortgage payments. If home prices have been rising for some time, then homeowners are likely to have positive home equity, which can be tapped with home equity loans or cash-out refinances. If the financial problems are permanent, then positive equity allows a house to be sold for enough money to pay off the outstanding balance on the mortgage. But when house prices are flat or falling, a household's financial problems cannot be ameliorated by a mortgage refinance, home equity loan, or sale. In such cases, it matters little whether the problem occurs before or after the mortgage resets, and the pattern of defaults among the 2006 loans indicates that many household-level problems are coming before the resets. In the next section, we show that falling housing prices are fundamentally related to defaults in ways that have nothing to do with subprime resets. Unfortunately, problems in both the subprime and prime mortgage markets are likely to be more intractable as a result. 


\subsection{Fact 2: Higher foreclosure rates stem from falling house prices}

The easiest way to show the tight link between house prices and foreclosures is to plot the data, as is done in Figure 5. The foreclosure rate is calculated directly from the Warren Group data, and house price growth is based on the repeat-sales index we constructed from the same dataset. The figure shows that Massachusetts house prices declined in the early 1990s and late 2000s, precisely the times when foreclosures rose. In this section, we provide evidence that this relationship is causal, in that falling housing prices cause foreclosures. While a causal relationship between prices and foreclosures is a long-standing tenet of housing research, we also argue that this relationship is more complex than it is typically modelled in the literature.

Figure 5: Foreclosures and Housing Prices in Massachusetts, 1990:q1-2008:q1

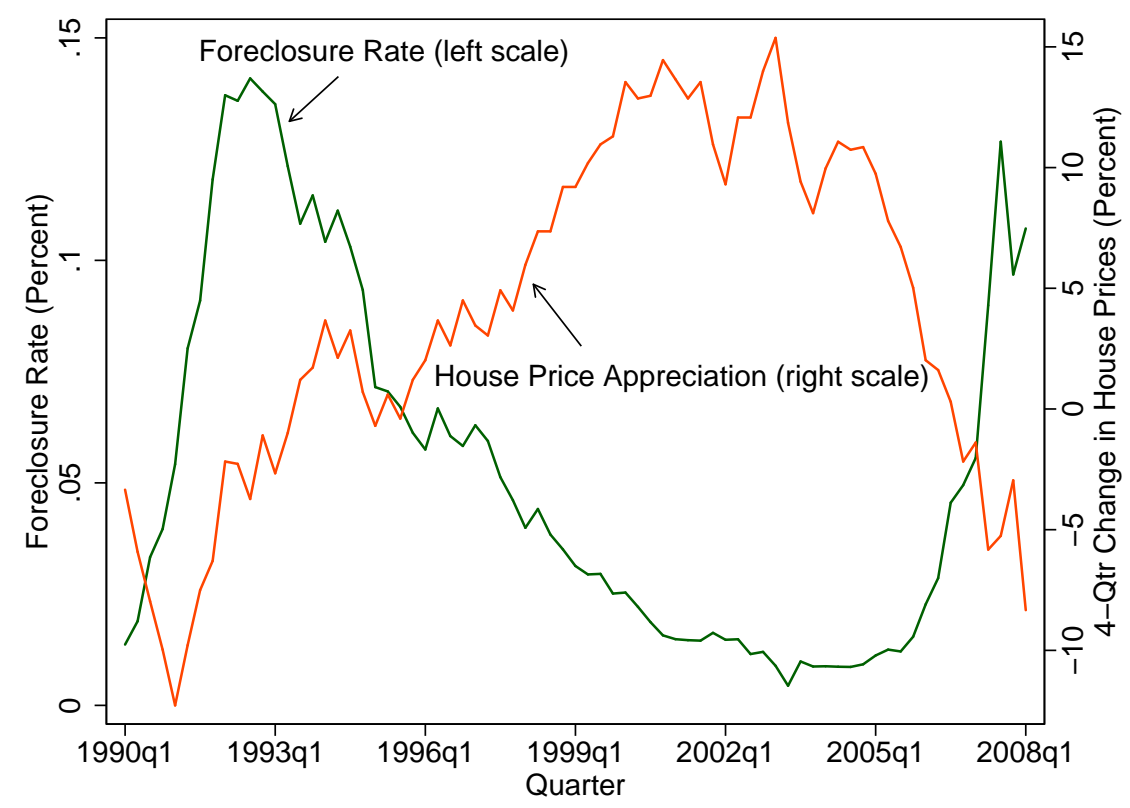

\subsubsection{Falling prices, negative equity, and foreclosures}

There are strong theoretical reasons to believe that falling house prices lead to rising foreclosures. Lower prices increase the likelihood that a borrower has negative equity, which occurs when the outstanding balance on the mortgage exceeds the value of the house. Negative equity, in turn, is a necessary condition for default. A borrower whose house is worth more than the mortgage can always sell the home, discharge the mortgage, and 
pocket the difference. The only reason someone would find themselves in foreclosure is if they had negative equity and could not retire the mortgage with a profitable sale.

The experience of the Massachusetts housing market during the 2001 recession provides striking support for the view that because negative equity is a necessary condition for default, foreclosure waves do not occur without declines in housing prices. Figure 6 graphs the foreclosure rate from the previous figure along with the state's 30-day delinquency rate, according to data from the Mortgage Bankers Association. During the 2001 recession, the national unemployment rate rose from 4.0 percent in 2000 to 6.0 percent in 2003. Massachusetts, with its sizable high-technology sector, suffered relatively more during this period, as its unemployment rate rose from a very low 2.7 percent in 2000 to 5.8 percent in 2003. Figure 6 shows that the loss of so many jobs caused many Massachusetts residents to miss mortgage payments. In 2001, the state's 30-day delinquency rate rose sharply and reached its highest level up to that time.

Figure 6: Foreclosures and 30-Day Delinquencies in Massachusetts, 1990:q1-2008:q1

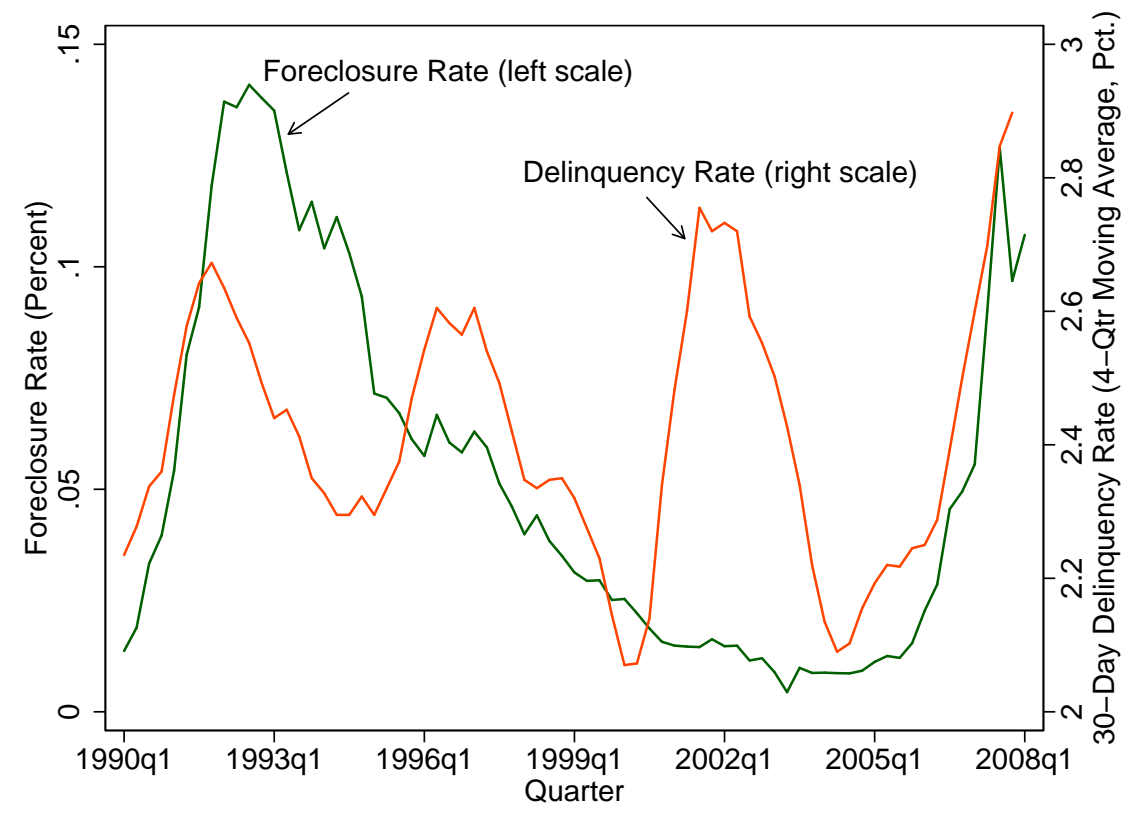

But while mortgage delinquencies rose during the 2001 recession, foreclosures did not. The Massachusetts housing cycle had become decoupled from the overall business cycle by the early 2000s, a situation mirrored in the national housing market. Consequently, Bay State housing prices kept rising even as the state's unemployment rate rose. So, while many people lost their jobs and missed mortgage payments during and immediately after the 2001 recession, few people lost their homes. In fact, like the high delinquency rate, the 
Massachusetts foreclosure rate also set a record in 2001 - but in the opposite direction, as foreclosures fell in 2001 to their their lowest level up to that time period. As theory would predict, without a drop in house prices that generates a large number of homeowners with negative equity, foreclosures will not rise. Owners will refinance or sell their homes in response to income shocks that cause them to miss mortgage payments. ${ }^{31}$

\subsubsection{Estimates of the effect of falling house prices on foreclosures}

The preceding figures illustrate the close relationship between falling house prices and foreclosures at the aggregate level. Because the Warren Group data include information on individual ownership experiences, we are also able to estimate the direct effect of house prices, or, more specifically, accumulated house price appreciation, on individual foreclosures. Homeowners purchase their houses at different times, so two owners with otherwise similar houses, living in the same neighborhood, have typically accumulated different levels of house price appreciation. These differences in accumulated appreciation turn out to be strong predictors of foreclosure. Figure 7 shows quarterly foreclosure probabilities for homes with different levels of cumulative house price appreciation in the Warren Group data. A borrower who has seen his property's value fall by more than 20 percent since the initial purchase is more than 15 times more likely to lose the home to foreclosure relative to someone who has seen his property appreciate by 20 percent.

The econometric model of GSW (2007) allows a more precise estimate of the houseprice effect on foreclosures by controlling directly for other observable variables, such as initial LTV ratios, neighborhood characteristics, interest and unemployment rates, and the type of residence (that is, single-family, condominium, or multi-family). This model also allows counterfactual experiments; for example, we can ask what foreclosures for a particular purchase-year cohort of homes would have looked like if this cohort had enjoyed a different level of house price appreciation. Figure 8 explores what would have happened to the 2005 cohort of borrowers had their homes appreciated as much as the 2002 borrowers' homes, all other factors held constant. The solid lines in this figure show that, in reality, the two cohorts have displayed strikingly different foreclosure probabilities. Owners from the 2005 cohort, who bought at the peak of the recent housing boom, are defaulting much more often than those from the 2002 cohort, who have enjoyed substantial house-price appreciation. However, the econometric model implies that foreclosures among the 2005 cohort would have more closely resembled the experience of the 2002 pool had the 2005 cohort enjoyed

\footnotetext{
${ }^{31} \mathrm{~A}$ practical implication of this fact is that the amount of home equity "destroyed" in foreclosure waves is likely to be limited. If homeowners have much equity in their homes to lose, then foreclosures are unlikely to occur in the first place.
} 
Figure 7: Foreclosure Rates and Cumulative House Price Appreciation (HPA) Since Purchase

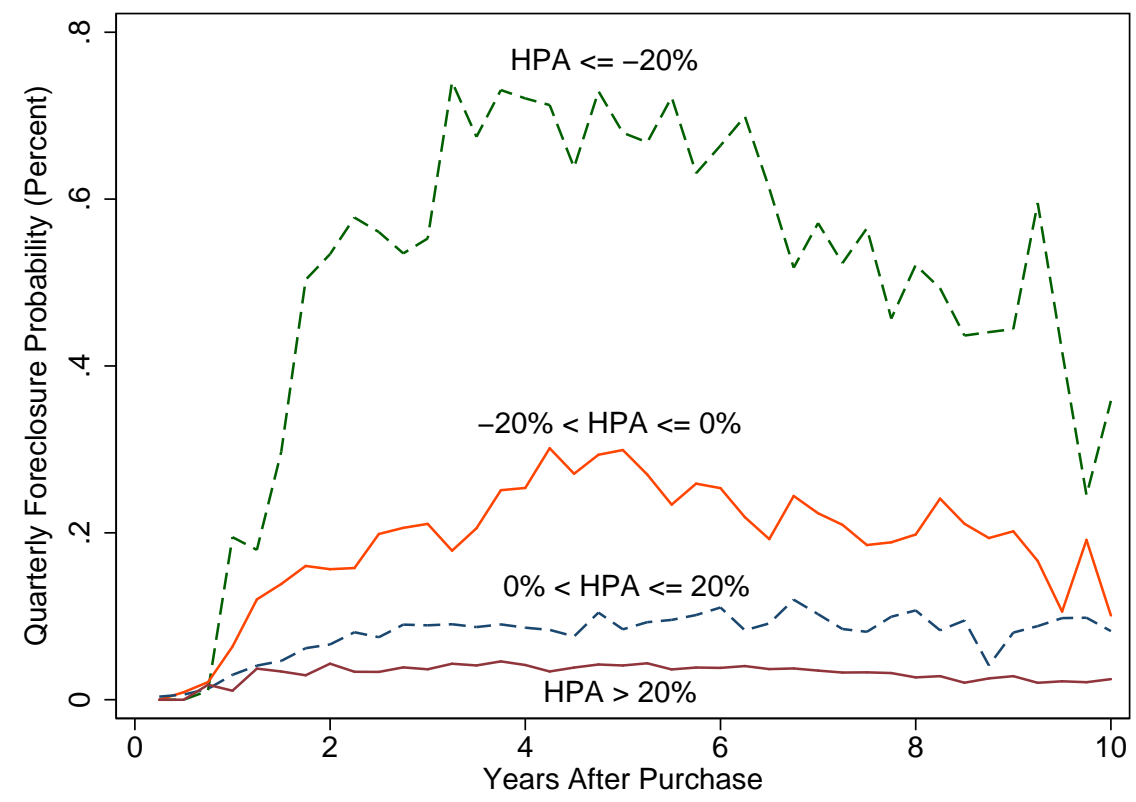

the sizeable house price appreciation that accrued to the comparison cohort. It is true that the 2005 cohort would have still had higher foreclosures than the 2002 group, even with the same house price appreciation. ${ }^{32}$ Even so, foreclosures among the 2005 group would have been nowhere near what actually occurred.

\subsubsection{Why negative equity is not a sufficient condition for mortgage default}

The previous analysis shows that negative equity is strongly predictive of default at both the aggregate and individual levels. But it is important to note that in no sense is negative equity a sufficient condition for default. In other words, virtually all foreclosed homeowners have negative housing equity, and periods of falling prices are also periods of rising foreclosures. But even when house prices are falling and many people have negative equity, the vast majority of these "underwater" or "upside down" homeowners do not default. A companion paper (Foote, Gerardi, Willen 2008) provides some empirical and theoretical support for the idea that negative equity is not a sufficient condition for default. First, using the Warren Group data, this paper identifies Massachusetts homeowners in the early 1990s who were likely to have negative equity, given the prices they paid for their homes

\footnotetext{
${ }^{32}$ This increase most likely results from the higher incidence of subprime loans among the 2005 cohort. Below, we discuss why subprime loans are likely to be more sensitive to house-price declines than prime loans.
} 
Figure 8: A counterfactual comparison of the actual performance of the the 2002 and 2005 cohorts with our estimate of how the 2005 mortgages would have fared had they enjoyed the house price appreciation (HPA) of the 2002 mortgages.

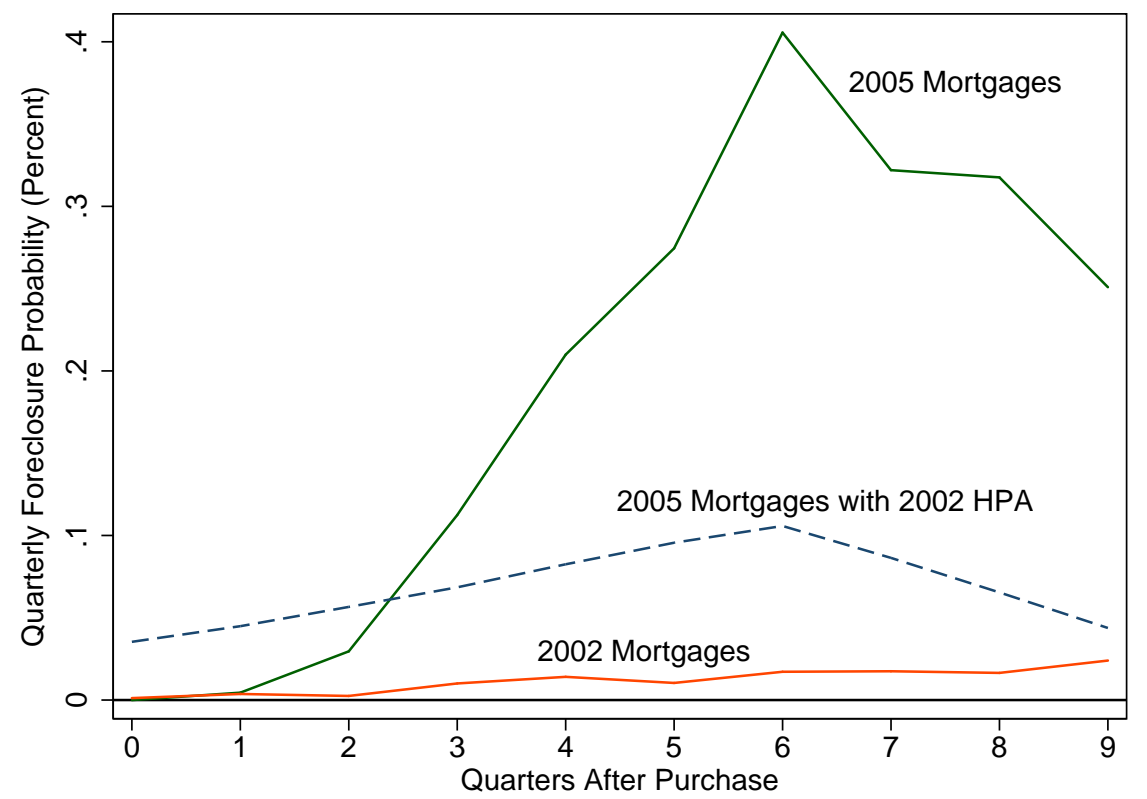

and the subsequent fall in housing prices. The paper then shows that less than 10 percent of these homeowners actually defaulted.

If all owners with negative equity do not default, then what determines which owners will default? As in other economic decisions, there is a marginal cost-benefit calculation involved: the homeowner weighs the marginal benefits of keeping the mortgage current against the marginal costs of doing so. The second part of the companion paper discusses this calculation in some detail, but we can give the basic intuition for it with an unlikely but instructive example. Consider a homeowner who purchases a $\$ 500,000$ home with an interest-only mortgage. A year after he purchases the house, a housing crash reduces the market value of home to only $\$ 100,000$. He now has negative equity of $-\$ 400,000$. Should he make his next mortgage payment, or should he default?

The homeowner gets two main benefits from making his mortgage payment. The first is that he can keep living in the house and avoid paying rent to someone else. Additionally, if the price of the house recovers in the next time period, he can sell it, retire the outstanding mortgage of $\$ 500,000$, and keep the difference. Denoting the next-period price of the house 
as $P_{t+1}$, the benefit $B$ of making the mortgage payment is

$$
B=\operatorname{Rent}+\left(P_{t+1}-\$ 500 K\right) .
$$

Now consider the cost $C$ of making the next mortgage payment. This is just the dollar value of the mortgage payment itself, so we can write

$$
C=\text { Mortgage payment. }
$$

The homeowner will default if the benefits from keeping the mortgage current are smaller than the costs. Subtracting the cost $C$ from the benefit $B$ gives

$$
B-C=(\text { Rent }- \text { Mortgage payment })+\left(P_{t+1}-\$ 500 K\right) .
$$

One notable feature of this expression is that it does not involve the current market price of the house $(\$ 100,000)$. There is a price term in this expression, but it is the future price of the house, $P_{t+1}$. So the fact that the homeowner now has negative equity in the home is not directly relevant to his default decision.

The fact that the future price matters in the default decision, while the current price does not, is not merely an academic point. Even if housing prices do not change, the importance of the future price has profound effects on the default decision. Assume that our homeowner is fairly sure that house prices were not going to recover, so he knows with near certainty that $P_{t+1}$ is going to equal to the current price of $\$ 100,000$. Plugging this value of $P_{t+1}$ into the expression above would appear to make the value of $B-C$ strongly negative. This negative value would then seem to imply that the benefit of keeping the mortgage current is much smaller than the cost of doing so. But this logic misses a crucial feature of the default decision, as pointed out by Kau, Keenan, and Kim (1994). If, in the future, housing prices have not recovered, then the owner can default in the future. If he does so, then the owner will not receive the value of the house, $P_{t+1}$. But a default also means that he will not have to pay back the mortgage balance of $\$ 500,000$, either. Thus, in the future, the owner will receive the greater of two quantities: either the excess of the houses's value over the outstanding mortgage $\left(P_{t+1}-\$ 500 k>0\right)$, or, in the case of a future default, nothing. Hence, today's benefit-cost calculation is more accurately described as

$$
B-C=(\text { Rent }- \text { Mortgage payment })+\max \left(P_{t+1}-\$ 500 K, 0\right) .
$$

This expression makes clear that the option to default later essentially prevents the future 
"capital gain" term in the owner's default decision from falling below zero. If this term cannot fall below zero, then the entire expression $B-C$ is much less likely to be negative, and the probability of a default today is sharply reduced.

Two remarks are useful here. First, the reluctance of the homeowner to default in this case has nothing to do with any transactions costs of defaulting. Even if the homeowner faced no social or financial stigma from default (such as a lower credit score), he is still better off keeping the mortgage current as long as the benefit-cost calculation above works in favor of doing so. Second, it is true that the owner in our example could default on his mortgage, and buy an otherwise identical house for only $\$ 100,000$. He would then pay a smaller monthly mortgage payment. However, as long as keeping his current home makes sense given the cost-benefit calculation above, then he should purchase the additional home and rent it out while keeping his current one. The fact that the second house is a "better deal" than the first in no way reduces the profitability of keeping the first one.

\subsubsection{Understanding why some people default and others do not}

The benefit-cost logic of the previous subsection, sometimes called the frictionless option model, is well-known in the housing finance literature. Even so, housing researchers have run into trouble when confronting this theoretical model with empirical data. Specifically, in the real world, borrowers with negative equity who appear to face the exact same benefit-cost calculation often default at different rates. The challenge for housing research is to explain this individual-level variation in default probabilities.

Much of the recent literature addresses this problem by positing that some homeowners are more cold-hearted than others. While some homeowners might have qualms about walking away from their mortgages - even if the benefit-cost calculation above implies that default is the most profitable option - other homeowners may have no such qualms. This explanation is sometimes called the "ruthless default" model, because it predicts that only ruthless people are able to bear the psychic costs of dishonoring their debts or the emotional toll of leaving their homes. ${ }^{33}$ A similar tack is taken by researchers who introduce other costs into the cost-benefit calculation. Such costs might include moving expenses, or the adverse consequences of damaged credit scores. If these more tangible costs of default vary within a group of individuals, then default probabilities of these individuals will also vary.

We take a different approach to the problem, an approach we believe proves useful in understanding the high rate of subprime defaults witnessed today. Empirical data often show that individual default probabilities rise when the owner is both in a position of

\footnotetext{
${ }^{33}$ For a review of this literature, see Vandell (1995).
} 
negative equity and is going through a difficult financial period, such as an enduring spell of unemployment or elevated expenses. This empirical pattern is hard to reconcile with costbased explanations of default probabilities. For example, why should "more ruthless" people, or people who face lower tangible default costs, be more likely to experience unemployment or high medical costs? However, this empirical finding does suggest a theory of varying default probabilities that is based on differences in the perceived benefits of staying in the home. This theory posits that the benefits of staying in the home vary because the capitalgain term in the cost-benefit calculation above is valued differently by different people. ${ }^{34}$

The previous benefit-cost calculation assumes that the homeowner values a dollar in the next period the same as he values a dollar today. This approximation will be closer to the truth for some homeowners than for others. Owners with stable jobs and some rainyday savings in the bank can afford to be patient with respect to future capital gains. In economic terms, these owners have low discount rates, meaning that they do not value a dollar in the future much less than they value a dollar today. Other homeowners are likely to be in a different situation with respect to how they value the future versus the present. Homeowners who have lost their jobs and have few financial resources to draw on are likely to attach a steep discount to future payoffs. These homeowners need money now — not later-so they are quite willing to give up potential future payoffs in return for current gains. ${ }^{35}$ The high discount rates of these owners reduce their valuation of the expected capital gain term above. If such owners are able to find places to live that cost less than their current mortgage payments, then the loss of potential capital gain is less likely to keep them from defaulting.

We can illustrate this implication with a concrete and realistic example. Consider someone who purchased a home in Massachusetts for $\$ 250,000$ in 1989 , which was the peak of the state's late-1980s/early-1990s housing cycle. By early 1993, this homeowner was likely to be far underwater on his mortgage, because housing prices fell on average by nearly 25 percent from 1989 to 1993. Fortunately, for this owner, large house price appreciation was soon to accrue. Massachusetts housing prices started rising again in the late 1990s, and by 2007, a house purchased for $\$ 250,000$ in 1989 was worth $\$ 505,000$, according to our repeat-sales price index. Unfortunately, back in 1992, not every Massachusetts homeowner with negative

\footnotetext{
${ }^{34}$ In addition to the companion paper (Foote, Gerardi, Willen 2008), the following theoretical explanation is spelled out more formally in GSW (2007).

${ }^{35}$ In economic terms, homeowners who are unemployed and without savings are liquidity constrained, because they cannot access liquid funds easily or cheaply. The rate at which they discount future payoffs is essentially the rate at which they can borrow, and if they can only borrow on credit cards, then their discount rates can easily exceed 20 percent. By contrast, for a homeowner with savings, the opportunity cost of consuming today versus the future is the rate of return on his savings; or, in economic terms, the cost of borrowing from himself. His discount rate is therefore much lower.
} 
equity had the financial wherewithal to stay in his home, because of the severe effects of the early 1990s recession. Those underwater owners who had lost their jobs and did not have adequate precautionary savings did not have the luxury of weathering the drop in housing prices in hopes of reaping price gains at a later date. Consequently, for these owners, the future benefits of staying in the home were smaller than the immediate payoffs of default, so they defaulted.

In short, we believe that it is more accurate to view differences in default probabilities among owners with negative equity as a function of how these owners view the future payoffs of staying in their homes, not in how they value the present costs of default. This line of thinking is particularly useful for understanding today's subprime foreclosure crisis. As we will see, the subprime market essentially created a class of mortgage borrowers whose ownership experiences were exceptionally sensitive to whether house prices were rising or declining. When housing prices fell, subprime owners were more likely to experience negative equity. And when negative equity occurred, subprime owners were more likely than other underwater homeowners to default. To flesh out this story, we must understand more about the risk characteristics of subprime loans, a task we take up in the next section.

\subsection{Fact 3: Prime lenders would have rejected most of the loans originated by subprime lenders}

In popular accounts, the subprime market is primarily defined as one that serves borrowers with poor credit histories. ${ }^{36}$ Yet the subprime mortgage market cannot be characterized along the single dimension of borrower credit quality, because subprime loans were riskier than prime loans for a number of other reasons as well.

Figure 9 presents information on the risk characteristics of subprime loans in Connecticut, Massachusetts, and Rhode Island, as measured by the Boston Fed's LoanPerformance dataset. The upper left panel focuses on FICO scores. The higher line in the figure is simply the fraction of subprime borrowers that had a FICO score of 620 or higher. This fraction rises from slightly less than 40 percent in 1999 to around 70 percent by 2004. Increases in the fraction of high-FICO borrowers in subprime pools have also been found in other nationwide datasets. These increases suggest that the quality of the subprime pool is getting better over time.

Yet plotting average credit scores presents an incomplete picture of the riskiness of subprime loans along other relevant dimensions. The lower line in the upper left panel of

\footnotetext{
${ }^{36}$ As noted in the introduction, the dividing line that typically places a borrower in the subprime class is a FICO score of 620 or lower.
} 
Figure 9 plots the fraction of subprime loans for which the borrower had a credit score of 620 or higher, the debt-to-income (DTI) ratio on the loan was 40 percent or less, the LTV ratio was 90 percent or less, and full documentation of the application was provided. This fraction begins at about 13 percent in 1999 and falls to around 5 percent by 2006. In contrast to the graph of borrower credit scores, this more complete measure of subprime loan quality is getting worse over time.

The opposite movements of the two lines can be reconciled by asking why the share of high-FICO borrowers is rising over time. One reason typically offered for the presence of high-FICO borrowers in the subprime market is that they were inappropriately steered there by unscrupulous mortgage brokers in search of higher commissions. While this is a possibility, high-FICO borrowers will also show up in the subprime pool if they desire mortgages that are riskier than those offered by prime lenders.

The upper right panel of Figure 9 illustrates this point by showing the evolution of average LTVs for different cohorts of subprime borrowers. The horizontal axis groups borrowers into seven categories based on their credit scores. Each line in the figure represents a two-year cohort of subprime loans. For the earliest cohort (1999-2000), the average LTV is around 80 percent for borrowers in the lowest category, suggesting an average downpayment of 20 percent. The LTV is only slightly higher for borrowers in this cohort with the highest credit scores. As the years pass, however, the difference in LTVs across different FICO classes begins to grow. By 2005-2006, average LTVs for the lowest-score borrowers had risen to around 85 percent, but average LTVs for the highest-score borrowers had surged to near 95 percent. Because the previous figure showed that the fraction of high-FICO borrowers was rising over time, we can infer from this figure that average LTV for the entire subprime pool was rising as well.

The lower left panel of Figure 9 provides a similar analysis for documentation status. In the earliest years of the sample, the fraction of fully documented loans made to the lowestFICO borrowers was between 70 and 80 percent. The corresponding fraction for high-FICO borrowers was about the same. But in 2001, the fraction for high-FICO borrowers began to fall. By 2005-2006, the fraction of fully documented loans or high-FICO borrowers had declined all the way to 40 percent, even though the corresponding fraction for the low-FICO borrowers had changed only a little since the start of the sample. Qualitatively, this pattern resembles that of the previous graph of LTVs; the riskiness of the entire subprime pool grew because of the behavior of the high-FICO borrowers.

The lower right panel Figure 9 displays the third indicator of loan risk, the DTI ratio. Early in the sample, DTIs for the lowest-FICO borrowers in the subprime pool were somewhat higher than those of the highest-FICO borrowers. The subsequent behavior of 
Figure 9: Alternative Measures of Risk in the Subprime Pool. Figures are generated from all newly originated subprime mortgages in the Boston Fed's LP dataset, including both purchase and refinance loans.
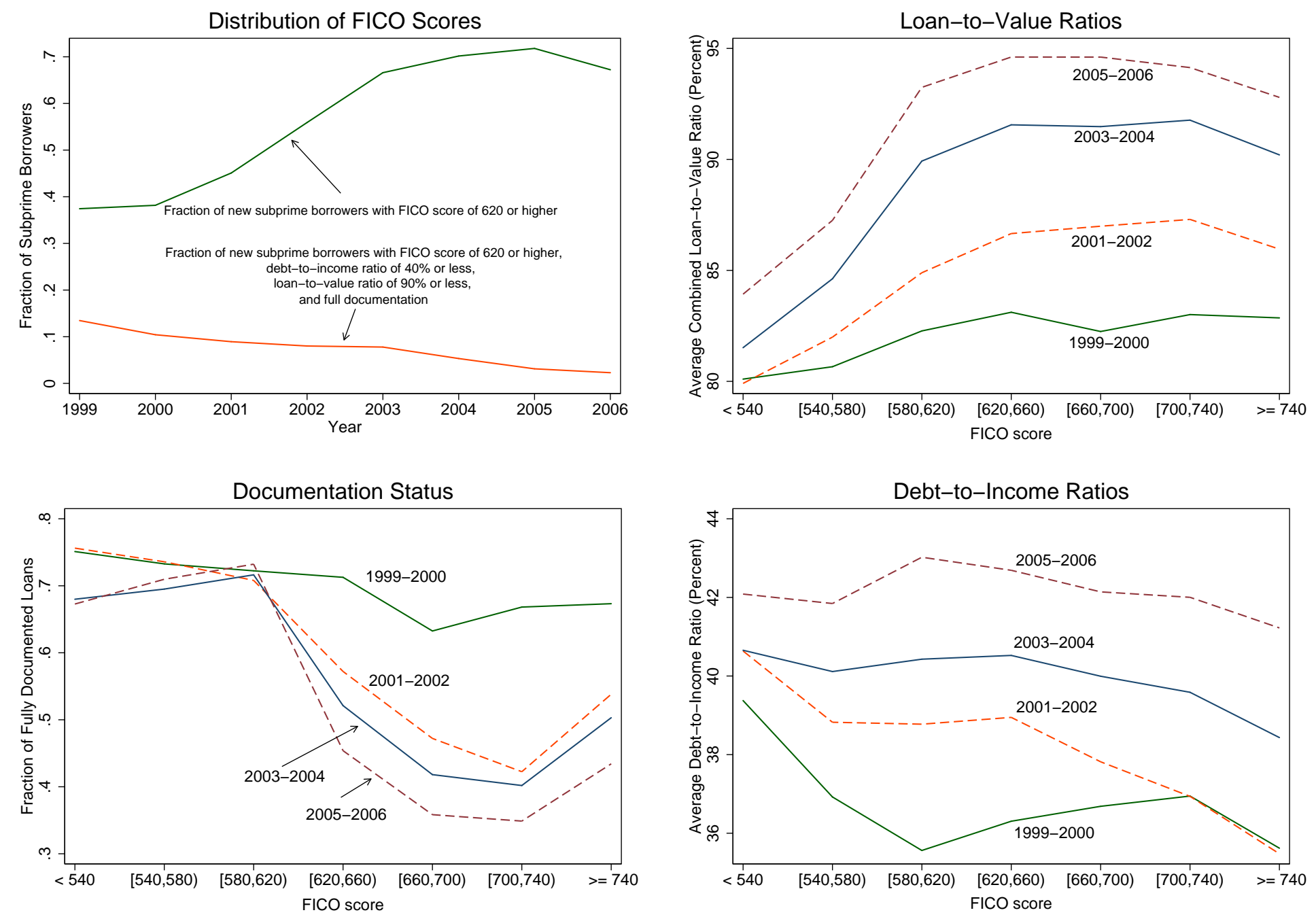
this characteristic is different than that of the previous two characteristics, in that DTIs deteriorated for borrowers of all FICO classes, not just the high-FICO borrowers. By the end of the housing boom, average DTIs for all borrowers reached more than 42 percent.

Taken together, the three risk characteristics - LTVs, documentation status, and DTIs tell a consistent story. All of these indicators moved in the direction of greater risk as the housing boom progressed and house prices moved higher. For LTVs and documentation status, most of this movement was caused by borrowers with high credit scores who were entering the subprime pool in larger numbers. In all likelihood, it would have been impossible for these borrowers to find prime lenders willing to make loans as risky as the subprime loans they eventually obtained. Prime lenders would have required larger downpayments, they would have insisted on lower DTI ratios, and they would have demanded better documentation of income and assets.

From a policy perspective, a crucial question is whether some of the high-FICO borrowers were inappropriately steered into loans whose risk characteristics made them unattractive for the cheaper prime market. It is possible that little such coercion occurred. Mortgage brokers may have simply found subprime lenders that were willing to make the loans that high-FICO borrowers themselves had determined were appropriate, given the market prices of the homes that these borrowers hoped to purchase. As housing prices moved higher, perhaps the high-FICO borrowers felt comfortable buying increasingly expensive homes, even though these purchases could only be financed with risky mortgages. We return to this issue when we discuss some outstanding questions in the conclusion of the paper.

In any case, the problem of "potentially prime" borrowers stuck in subprime loans is mitigated by the risk-based pricing models used by most subprime lenders. Using the LP data, we calculated the percentage of subprime loans for owner-occupied homes that had an LTV cutoff of 90 percent or below, that were fully documented, that had borrower FICO scores of 620 or higher, and had a DTI of 45 percent or less. About 9.6 percent of the subprime mortgages in the LP data met all of these criteria, so about 10 percent of the borrowers with outstanding subprime loans could qualify for prime loans. The important question is whether these borrowers are paying the onerous terms typically associated with subprime loans. Of these borrowers, approximately 65 percent have a fixed interest rates. Furthermore, the average initial interest rate for these loans is 6.7 percent, the median is 6.6 percent, and the 90th percentile rate is 7.9 percent. By contrast, only 29 percent of all subprime loans in the dataset are fixed-rate instruments, and the average interest rate calculated over all subprime loans is 7.7 percent (90th percentile is 9.4 percent). This calculation shows that the borrowers that can be identified as "potentially prime" already have more favorable mortgage terms than the typical subprime borrower. 
Analysis of changing risk characteristics among subprime mortgages also illustrates why subprime mortgages have proven so vulnerable to declines in house prices. Recall that a foreclosure typically occurs when two events happen at the same time: a borrower must be underwater on the mortgage and must have experienced some shock that sharply raises the value of a dollar received today relative to a dollar received later. An increase in any of the risk characteristics analyzed in this section makes these conditions more likely when housing prices drop:

- High loan-to-value ratios mean that at the time of purchase, the owner has little equity in the house. A subsequent decline in house prices is therefore more likely to result in the negative equity that is a necessary condition for default.

- High debt-to-income ratios indicate that the mortgage was burdensome to the borrower even before any income shock lowered current consumption. Hence, the increase in current consumption that occurs immediately after the mortgage payments are suspended is greater, making default more likely.

- Low documentation has a "multiplier" effect that inflates the impact of the other measured risk characteristics. A borrower who has exaggerated his income will have a higher DTI ratio than is listed on his mortgage application. This makes the high-DTI channel more likely to lead to foreclosure.

- Borrower credit scores have a subtle relationship with house-price sensitivities that depends on why the borrower had a bad score to begin with. One reason for a low FICO score is that the borrower has little outside wealth and is subject to large and frequent income shocks. In the past, this combination might have led to defaults on credit cards or other loans, but these characteristics also make mortgage defaults more likely. Alternatively, the borrower could have a high discount rate, so that he values consuming in the present much more than saving for the future. These preferences would cause him to attach less value to future capital gains, again making default more likely.

In summary, the reasons why subprime mortgages have defaulted with such frequency as housing prices have fallen are varied and complex. The reasons are more complex, in fact, than they are often claimed to be in popular media accounts. Commentators often use the subprime crisis as Exhibit A for the claim that "some people should not own houses." Implicit in this view is the notion that the subprime market is wholly characterized by irresponsible borrowers with low credit scores, who lack the financial or emotional wherewithal 
to remain current on mortgages. Yet we have seen that subprime loans were also made to borrowers with high credit scores; unfortunately, these borrowers were generally more likely to have other risk characteristics that made them susceptible to price declines. Blaming borrowers with low credit scores for the subprime mess is a vast oversimplification of the problem.

\subsection{Fact 4: Many recent foreclosees put little money down and had lived in their homes a short time}

As noted earlier, an advantage of the Warren Group dataset is that it can generate complete ownership experiences by linking mortgages taken out by the same owner on the same house. We can therefore calculate the amount of money that a foreclosee invested in the home at the time of purchase, even if this owner subsequently refinanced into another mortgage before defaulting. Table 4 presents the distribution of combined purchase $\operatorname{LTVs}^{37}$ for borrowers who lost their homes to foreclosure in various years. On average, recent foreclosees bought their homes with mortgages that had high LTVs and (equivalently) low downpayments. Among 2007 foreclosees, 40 percent bought their homes with no downpayment at all, and more than half (53.4 percent) put down less than 5 percent. Of course, we have no information about whether these owners subsequently invested money in home improvements. But these figures provide strong evidence that most current foreclosees did not lose much accumulated savings when they lost their homes. The experiences of recent foreclosees contrasts sharply with those of Massachusetts residents who experienced foreclosure in 1991 and 1992. The last two rows of Table 4 show that during the earlier foreclosure wave, only about 10 percent of foreclosees put down less than 5 percent on their homes. About one in three put down 20 percent or more.

The availability of complete ownership experiences in the Warren Group dataset also allows us to measure the length of time that an owner lived in the home before foreclosure occurred. For the most recent foreclosees, this time was typically short. Table 5 shows that more than one quarter of 2006-2007 foreclosees owned their houses for less than two years, and more than 40 percent owned them for less than three years. To be clear, this is the entire homeownership experience, from the date that the owner closed on his new home to the date that he lost the title to it through foreclosure. Since the Massachusetts foreclosure process typically takes at least six months, these figures indicate that most recent foreclosees spent little time in their homes before financial problems occurred. Here again there is a

\footnotetext{
${ }^{37}$ Recall that a combined purchase LTV takes into account all of the mortgages used to purchase the home, including piggybacks.
} 
contrast with the previous foreclosure wave. In the early 1990s, more than three quarters of foreclosees had lived in their houses for more than three years.

Table 4: Loan-to-Value Ratios at Purchase Among Foreclosees, by Year of Foreclosure

\begin{tabular}{ccccc}
\hline \hline & $\leq 80 \%$ & $(80 \%-95 \%]$ & $(95 \%-100 \%)$ & $\geq 100 \%$ \\
\hline 2006 & 8.6 & 41.1 & 15.7 & 34.5 \\
2007 & 8.0 & 38.4 & 13.4 & 40.0 \\
\hline 1991 & 35.9 & 53.9 & 1.9 & 8.2 \\
1992 & 30.4 & 58.0 & 2.7 & 8.8 \\
\hline
\end{tabular}

Table 5: Ownership-Experience Lengths Among Foreclosees, by Year of Foreclosure

\begin{tabular}{ccccccc}
\hline \hline & $\leq 1$ year & $\leq 2$ years & $\leq 3$ years & $>3$ years & $>5$ years & $>10$ years \\
\hline 2006 & 4.0 & 26.9 & 42.4 & 57.5 & 42.3 & 21.8 \\
2007 & 3.1 & 25.8 & 45.1 & 54.9 & 38.8 & 21.1 \\
\hline 1991 & 5.8 & 11.7 & 24.8 & 75.1 &. & $\cdot$ \\
1992 & 3.2 & 6.6 & 15.3 & 84.6 &. &. \\
\hline \hline
\end{tabular}

What explains the differences in time and money invested across foreclosure cohorts? The most important factor is the different macroeconomic environments of the two foreclosure waves. As noted earlier, the national recession of the early 1990s had deep ramifications for Massachusetts. Additionally, a wave of residential overbuilding in the state during the mid-1980s left the Massachusetts housing market saturated with supply just as this recession occurred. High unemployment and previous overbuilding combined to exert strong downward pressure on the state's housing prices. According to the repeat-sales index constructed from the Warren Group data, Massachusetts housing prices fell 22.7 percent from 1988:Q3 to 1993:Q1. Price declines of this size meant that even someone who made a substantial initial downpayment was in danger of experiencing negative equity. During the current cycle, Massachusetts house prices have yet to decline by a similar amount, falling 12.0 percent from 2006:Q2 to 2008:Q1. The state's unemployment rate has also edged down during this time by 0.4 percentage point. A second factor affecting average LTVs among Massachusetts foreclosees is that high-LTV purchases became more common in the 1990s and early 2000s, as we saw in Table 1. To the extent that homeownerships are now more likely to begin with higher LTVs (and thus lower equity), we should not be surprised to see higher purchase LTVs among the current crop of foreclosees.

One influence on the time spent owning a home that is eventually lost to foreclosure is whether the home was owned by a speculative investor. Owners who purchase properties 
in hopes of "flipping" them for a profit later are usually among the first to default on their mortgages when house prices start declining. During the early 1990s foreclosure wave, contemporary accounts suggested that soured investments were responsible for a substantial fraction of foreclosures, especially among condominiums. This is somewhat puzzling given our findings, because a large investor presence in the earlier wave would have reduced the length of time that foreclosees owned their homes in that period. Unfortunately, identifying investors with any precision is difficult in currently available data. Although some investors do identify themselves as non-owner-occupants when applying for loans, many do not because owner-occupants qualify for lower mortgage rates.

\subsection{Fact 5: Current Massachusetts foreclosures involve a dispro- portionate number of multi-family dwellings}

From a theoretical standpoint, public policies addressing foreclosures are justified by the negative externalities that foreclosures exert on their communities. ${ }^{38}$ Foreclosed houses often sit empty and deteriorate, driving down the values of nearby properties. An additional externality that often accompanies a multi-family foreclosure is the eviction of tenants who rent apartments there. These evictions can make multi-family foreclosures more costly from a social perspective than foreclosures on single-family homes or condominiums. Unfortunately, multi-family defaults are especially numerous in Massachusetts today.

Figure 10 illustrates the importance of different types of residences in the state's housing market in general, and in the current foreclosure wave in particular. The left panel shows that purchases of single-family homes make up the lion's share of the Massachusetts housing market, with condos second and multi-families third. The right panel graphs the number of foreclosures. ${ }^{39}$ Foreclosures of single- and multi-family homes are now at or approaching previous levels, but the number of condominium foreclosures is much smaller relative to the previous foreclosure wave. ${ }^{40}$ Table 6 tabulates the shares of foreclosures during the two foreclosure waves. During the most recent wave, multi-family homes accounted for 28.4 percent of foreclosures, up from 20.4 percent in the early 1990s. Currently, multi-family residences are the only type of house whose foreclosure share is larger than its average purchase share from 1990 to 2007.

\footnotetext{
${ }^{38}$ Formally, a negative externality occurs when a person does something to adversely affect the well-being of others, but does not compensate them for doing so.

${ }^{39}$ Recall that the Warren Group dataset tracks purchases starting in 1987 and foreclosures starting in 1989.

${ }^{40}$ This pattern is consistent with the earlier discussion about the importance of investor condominiums during the early-1990s foreclosure wave.
} 
Figure 10: Purchases and Foreclosures in Massachusetts, by Type of Residence, 1987-2007
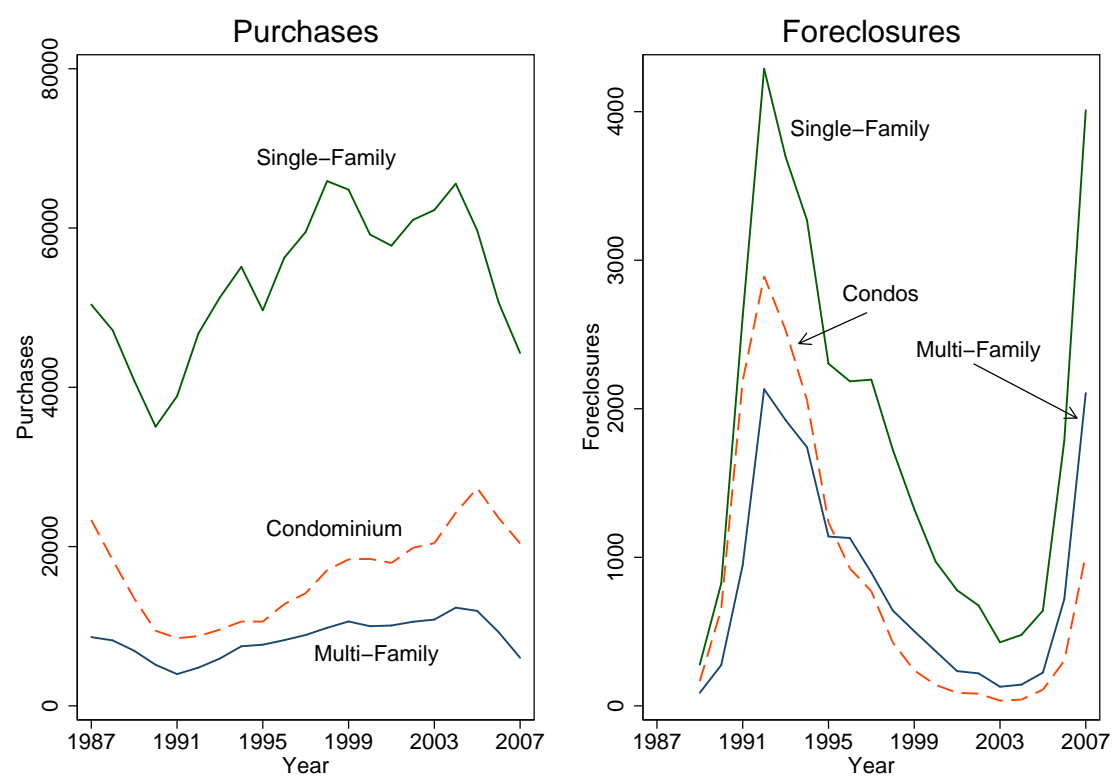

Table 6: Shares of Residence Types in Purchases and Foreclosures

\begin{tabular}{l|ccc}
\hline \hline & & & \\
& Single-Family & Condominium & Multi-Family \\
\hline 2006-2007 Foreclosures & $58.3 \%$ & $13.3 \%$ & $28.4 \%$ \\
1991-1992 Foreclosures & $45.9 \%$ & $33.7 \%$ & $20.4 \%$ \\
\hline 1990-2007 Purchases & $68.8 \%$ & $20.4 \%$ & $10.8 \%$ \\
\hline
\end{tabular}


To measure the default probabilities of different types of homes more precisely, we construct cumulative default hazards. A default hazard is the probability that a default takes place in a given time period, conditional on the fact that a default has not occurred up to that time. As the name suggests, a cumulative default hazard sums up the instantaneous probabilities of default over time. A cumulative default hazard is therefore a measure of how many foreclosures are likely to have occurred among a group of homes purchased in some year, as a function of how much time has elapsed since the purchases took place. ${ }^{41}$

Figure 11: Cumulative Default Hazards for Massachusetts Homes Purchased from 2001 to 2006, by Type of Residence

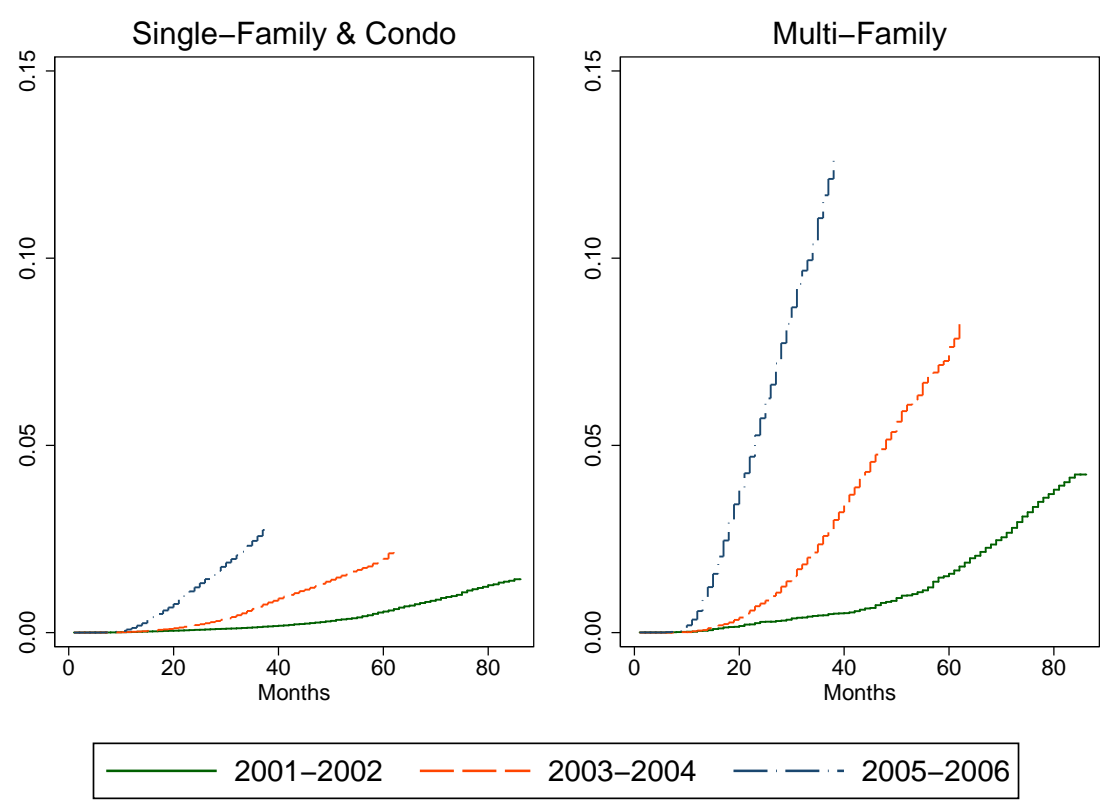

Figure 11 graphs foreclosure hazards for single-family, condos, and multi-family residences purchased from 2001 to 2006. The left panel corresponds to single-families and condos, while the right panel presents the data for multi-family homes. Both panels show that homes purchased in 2005 and 2006 are defaulting more quickly than homes purchased in either 2001-2002 or 2003-2004. The reason for this pattern is that rising housing prices during the early 2000s generated positive equity for homes purchased earlier, and, as we have seen, positive equity makes foreclosure unlikely. Yet while the qualitative pattern of

\footnotetext{
${ }^{41}$ The cumulative default hazard takes into account the fact that some homeownerships are "rightcensored" with respect to foreclosure. That is, in every period, some homeownerships end in a sale rather than foreclosure, and therefore drop out of the pool of potential foreclosures for the next period. As a result, a cumulative default hazard is not strictly the probability that a given house purchased in some period will be foreclosed some time later.
} 
defaults is the same across the two panels, the quantitative level of foreclosures is not. In the current foreclosure wave, multi-family homes are defaulting more than three times more quickly than single-families and condos purchased at the same time. ${ }^{42}$

Figure 12: Average Massachusetts Loan-to-Value Ratios at Purchase, by Type of Residence

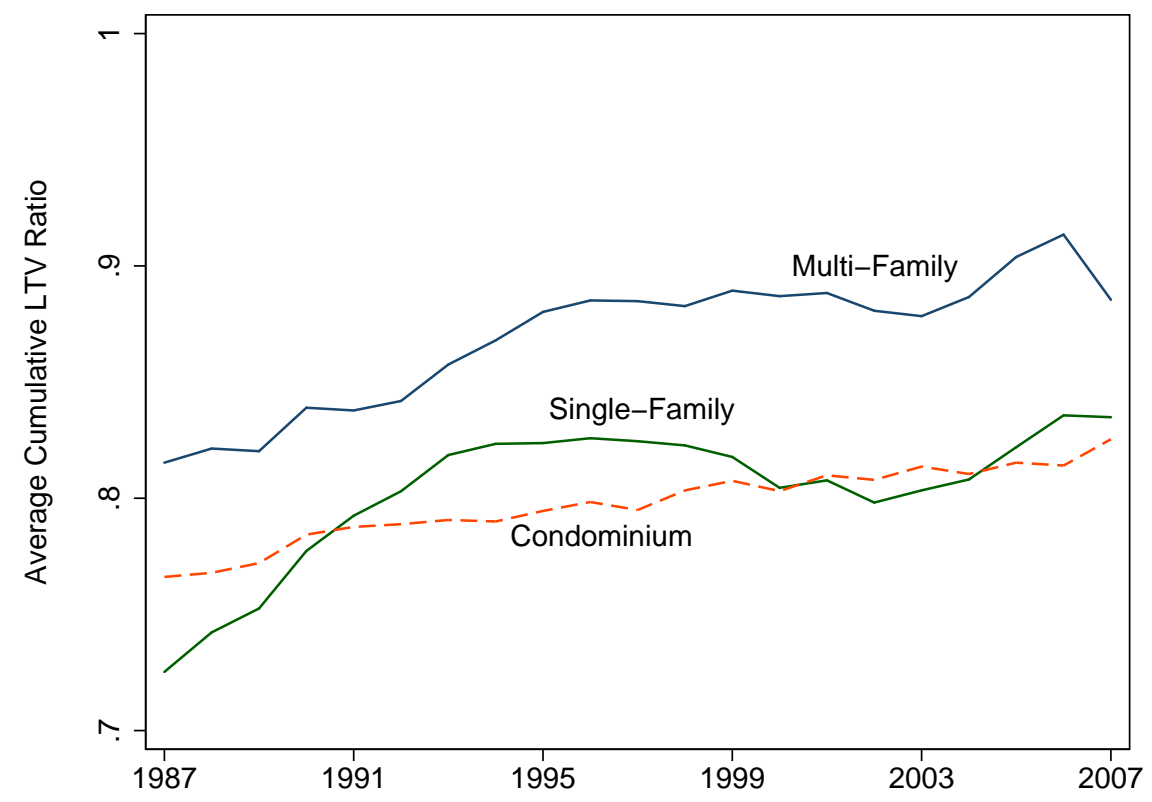

Why are multi-family foreclosure rates so high? To start with, multi-family houses are typically purchased with higher LTV ratios than either single-family homes or condominiums. Figure 12 graphs average LTV ratios for the three types of homes from 1987 to 2007. We saw in Table 1 that purchase LTVs were rising over this period. Figure 12 shows average LTVs for multi-family residences typically exceeded those for the other two types of homes by several percentage points, reaching 90 percent during the height of the recent housing boom. Multi-families would therefore be more likely to have negative equity as prices receded. Additionally, purchases of multi-family dwellings may have more of an "investment" quality to them than purchases of single-family homes or condos. Purchasers of multi-family residences sometimes qualified for purchase loans based on the rents they hoped to receive,

\footnotetext{
${ }^{42}$ In unreported work we replicated Figure 11 by breaking out foreclosure probabilities for three types of homes separately. The foreclosure probabilities for condominiums look similar to those for single-family homes, which justifies the choice to group these two types of homes together in Figure 11. When we repeat this exercise on foreclosures from the early 1990s, however, the data for condominiums looks much closer to that for multi-family homes. This is consistent with the view that condominiums were likely to be used as investment vehicles during the earlier housing cycle.
} 
even if the new owners planned to live in one of the units themselves. This strategy can turn out poorly if rental income is more sporadic or lower than the new owners had hoped.

Table 7: Fractions of Massachusetts Foreclosees from Low-to-Moderate Income (LMI) or Minority Areas

\begin{tabular}{c|cc|cc}
\hline \hline & \multicolumn{2}{|c}{ LMI \% of } & \multicolumn{2}{c}{ Minority Zip Code } \\
& Foreclosure & Ownerships & Foreclosure & Ownerships \\
\hline \hline 2006 & 43.8 & 16.8 & 25 & 14.2 \\
2007 & 44.2 & 17.0 & 25.6 & 14.3 \\
\hline 1991 & 34.1 & 17.7 & 21.8 & 14.8 \\
1992 & 38.8 & 17.6 & 23.3 & 14.7 \\
\hline
\end{tabular}

At this point it is useful to consider how the facts we have discussed so far affect demographic patterns of foreclosures. If members of particular demographic groups tend to have small downpayments, if they are more likely to have purchased homes recently, or if they are more likely to live in multi-family homes, then we would expect these groups to be more heavily represented among the current crop of foreclosees. A comparison of neighborhoods affected by foreclosures indicates some demographic differences across the two foreclosure waves. Compared to the early 1990s, recent foreclosees are more likely to come from zip codes with a preponderance of low-to-moderate income (LMI) residents or minority households than was the case in the early 1990s. ${ }^{43}$ Table 7 indicates that among the 2006-2007 foreclosees, about 44 percent came from LMI communities, while about one quarter came from zip codes with high levels of minority residents. These LMI and minority fractions are much greater than the underlying fractions for all homes in Massachusetts (about 17 percent and 14 percent, respectively). Foreclosees in the early 1990s were also more likely to come from LMI or minority areas, but these areas were not as highly represented among foreclosures as they are today.

\subsection{Fact 6: Most recently foreclosed homes in Massachusetts were purchased with prime mortgages}

The ability to construct complete ownership histories with the Warren Group data is also helpful in assessing the role of subprime purchase mortgages among current foreclosures. One of the ways in which subprime lending can raise the homeownership rate is by

\footnotetext{
${ }^{43}$ Low income zip-codes are defined to be zip codes in which the median household income is less than or equal to 50 percent of the state median, while moderate income zip-codes have median income values between 50 percent and 80 percent of the state median.
} 
providing a source of credit to segments of the market that have been traditionally underserved. However, if subprime lending places people into homes that are inappropriate for their financial circumstances, then the social benefits of subprime lending are obviously reduced. Knowing the precise fraction of foreclosed homes that was purchased with subprime mortgages is therefore important for housing policy research. Unfortunately, obtaining this measure is impossible unless mortgages within a single ownership experience can be linked together. ${ }^{44}$

A clear message that emerges from the Warren Group data is that ownerships that begin with subprime purchase mortgages end in default more often than ownerships that begin with prime mortgages. Figure 13 presents cumulative foreclosure hazards broken down by type of house, purchase year, and subprime-purchase status. This figure has the same structure as Figure 11, but now the cumulative hazards for prime and subprime purchases are presented separately. As we saw in Figure 11, homes purchased in 2001-2002 and 20032004 are less likely to be foreclosed upon than homes purchased in 2005-2006. Looking across the two columns, we see again that foreclosure rates for multi-family homes are higher than for single-family homes and condos. But comparing the two rows, we see that subprime purchases are more likely to default, no matter what the type of house. (Note the different vertical scales in the two rows.) For prime single-families and condos purchased in 2005-2006, the cumulative default hazard reached about 1.3 percent at the end of 2007. For the same types of homes purchased with subprime mortgages, the corresponding hazard was 11.9 percent. A large discrepancy in foreclosure rates also exists for multi-family homes. The cumulative hazard for multi-families purchased with subprime mortgages in 2005-2006 reached nearly 25 percent by the end of 2007 . The corresponding hazard for prime multifamilies was about 8 percent.

The high foreclosure probability among subprime purchases is a central finding of GSW (2007). That paper estimates foreclosure probabilities of prime and subprime purchases holding a number of other factors constant, such as LTV ratio at purchase, cumulative price appreciation during the ownership experience, and type of residence. This exercise shows that subprime purchases end up in foreclosure about six times more often than prime purchases, all else equal.

While it is true that subprime purchases tend to default more quickly than prime purchases, it is also true that in Massachusetts, subprime purchases, even at their peak, were a small share of the overall real estate market. Table 8 presents subprime purchase shares

\footnotetext{
${ }^{44}$ Consider an owner who purchases a house with a subprime mortgage, but refinances into a prime mortgage before he defaults. There is no way to know that this represents a default on a subprime purchase unless the purchase mortgage and defaulted mortgage can be traced back to the same owner. The same problem obviously occurs when a prime purchaser takes out a subprime refinance before he defaults.
} 
Figure 13: Cumulative Default Hazards for Massachusetts Homes Purchased from 2001 to 2006, by Type of Residence and Subprime-Purchase Status
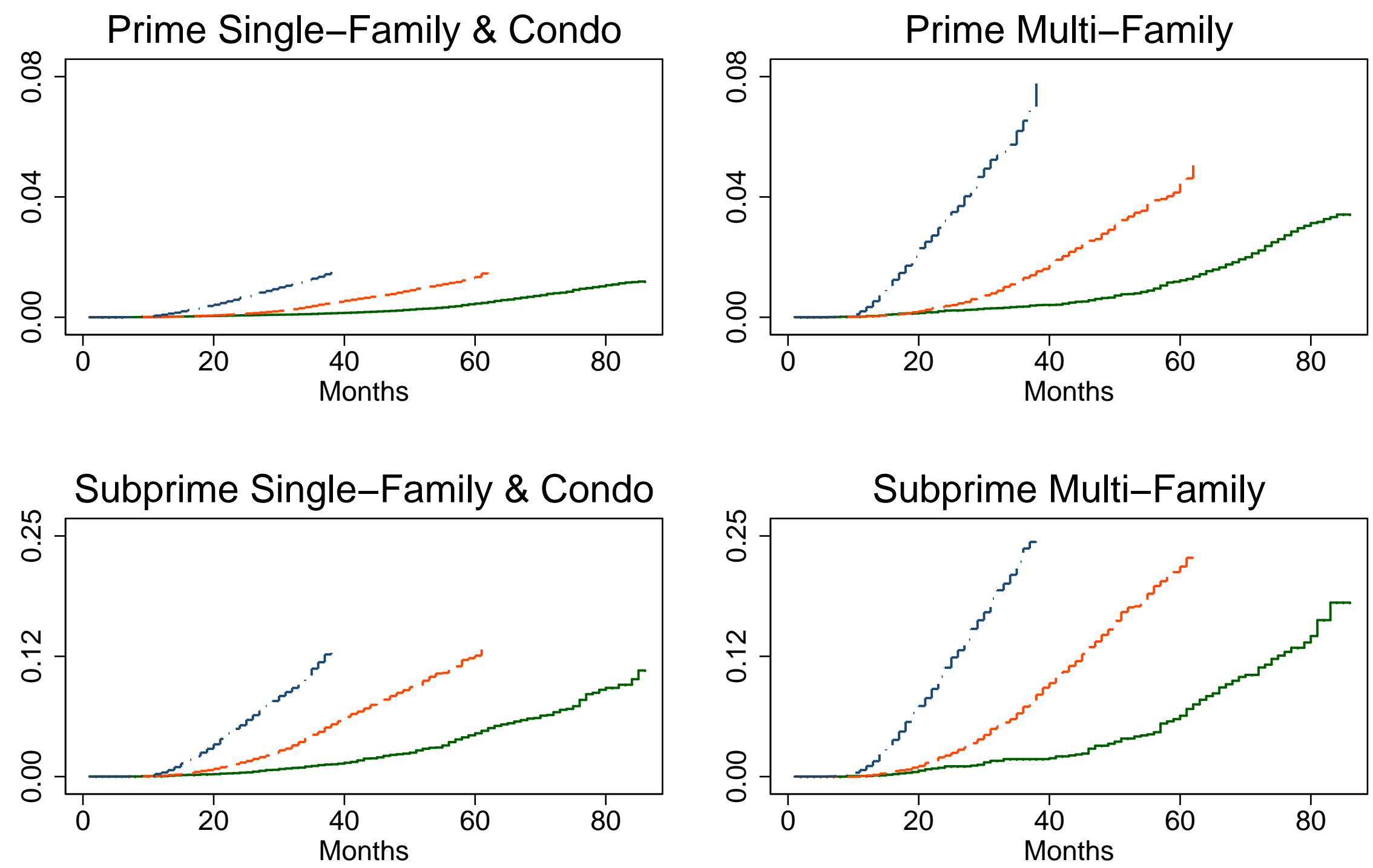

$$
\text { 2001-2002 - - 2003-2004 - - 2005-2006 }
$$


Table 8: Subprime Purchase Shares (in Percent) for Massachusetts Homes, by Type of Residence and Purchase Year

\begin{tabular}{lccccccccc}
\hline & 1999 & 2000 & 2001 & 2002 & 2003 & 2004 & 2005 & 2006 & 2007 \\
\hline Single-Family & 2.3 & 2.3 & 2.6 & 3.5 & 5.9 & 8.6 & 13.2 & 11.4 & 2.6 \\
Condominium & 2.2 & 2.1 & 2.2 & 2.5 & 4.3 & 6.0 & 10.7 & 10.7 & 3.4 \\
Multi-Family & 4.2 & 4.6 & 6.4 & 9.4 & 18.0 & 26.4 & 32.6 & 28.6 & 5.8 \\
\hline All & 2.5 & 2.5 & 3.0 & 4.0 & 7.0 & 10.1 & 14.8 & 13.1 & 3.1 \\
\hline
\end{tabular}

for each type of home from 1999 to 2007. After emerging in the mid-1990s, the subprime share for purchases in the Massachusetts housing market peaked at only 14.8 percent in 2005. Breaking out the numbers by type of residence, we see that subprime mortgages were used to purchase multi-family homes more often than either single-family homes or condominiums. In 2005, the subprime purchase share for multis peaked at nearly one-third (32.6 percent). But the subprime-purchase shares for the other two residence types were less than half that percentage. ${ }^{45}$

Figure 14 essentially combines the information on cumulative foreclosure hazards and purchase frequencies by presenting the shares of current foreclosures attributable to each of the six possible categories, which are based on the three types of residences (singlefamily, condominium, and multi-family) and the two types of purchase mortgages (prime and subprime). ${ }^{46}$ The figure shows that even though subprime purchases are more likely to default, the small share of subprime purchases in total purchases means that most homes recently lost to foreclosure were purchased with prime mortgages. Breaking down the data by type of home, subprime purchases are most important among foreclosures of multifamily homes, where they account for about 43 percent of all foreclosures. ${ }^{47}$ The corresponding figures for single-family and condominiums are only about 24 and 27 percent, respectively. Across all types of homes, 30 percent of foreclosures during 2006 and 2007 were purchased with subprime loans. The rest - fully 70 percent-were purchased with prime mortgages.

\footnotetext{
${ }^{45}$ Because the data in Table 8 come from the Warren Group, we use the subprime-lender classification from the HUD list to denote a subprime purchase. As noted earlier, this method will result in a misclassification if a subprime purchase mortgage is originated by a prime lender, or vice versa. Based on our checks discussed above, we believe that using the HUD list probably undercounts the number of subprime mortgages, so the figures in the table should be considered lower bounds. We discuss some robustness checks on our figures below.

${ }^{46}$ Note that for each type of house, the subprime and prime shares in foreclosures sum to the corresponding total share found in Table 6. For example, the 44.1 percent share of foreclosures for prime single-families and the 14.2 percent share for subprime single-families sum to the 58.3 percent single-family share that appears in the top row of Table 6.

${ }^{47}$ This figure comes from dividing the 12.2 percent share of foreclosures for subprime multi-families with the total foreclosure share for multi-families of 28.4 percent ( $=12.2$ percent +16.2 percent).
} 
Figure 14: Shares of 2006-2007 Massachusetts Foreclosures by Type of Residence and Subprime-Purchase Status

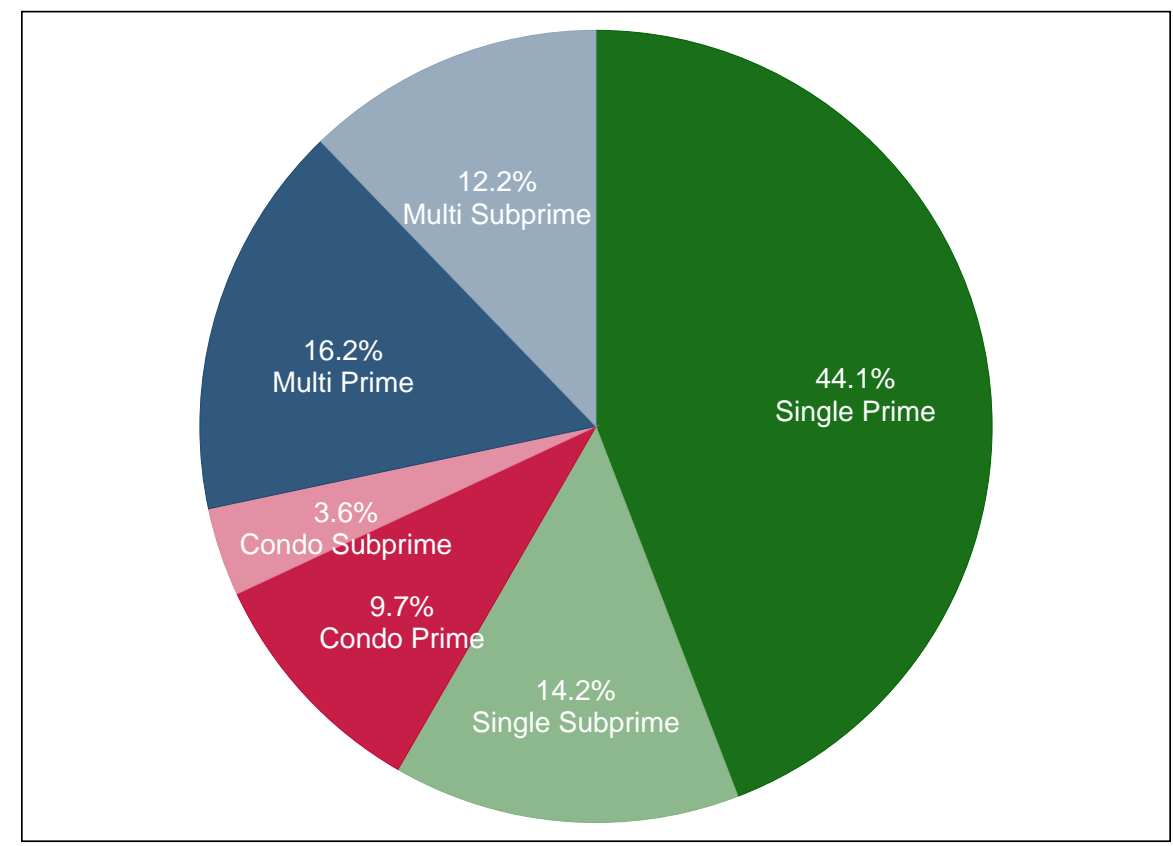

At this point, it is important to remember that we use the HUD subprime-lender list to assign subprime status to mortgages in the Warren Group data. This measure is subject to error, because lenders who originate predominately subprime mortgages also make prime loans (and vice versa). If using the HUD list undercounts the total number of subprime mortgages, then the importance of prime purchases in current foreclosures will be smaller than Figure 14 implies. Fortunately, the ability to link mortgages in the Warren Group data allows us to perform a robustness check on our results. Subprime lending is a relatively new phenomenon. Therefore, if we find that a large portion of foreclosed homes were purchased on or before 1999, then we have additional confirmation that prime purchases are an important component of the current foreclosure wave. Figure 15 presents the absolute numbers of 2006-2007 Massachusetts foreclosures grouped by type of house, subprime-purchase status, and year of purchase. The top panel plots the data for prime purchases. Of the 4,389 single-family foreclosures designated as prime purchases, almost half $(2,087)$ were purchased in 1999 or before. Across all types of homes, there were 6,961 prime purchases foreclosed upon in 2006 and 2007. Of these, 2,965 (42.6 percent) were purchased before 1999. Because the subprime market was relatively small at that time, this large share provides further evidence that homes purchased with prime mortgages are an important component of the current foreclosure wave. 
Houses Purchased with Prime Mortgages

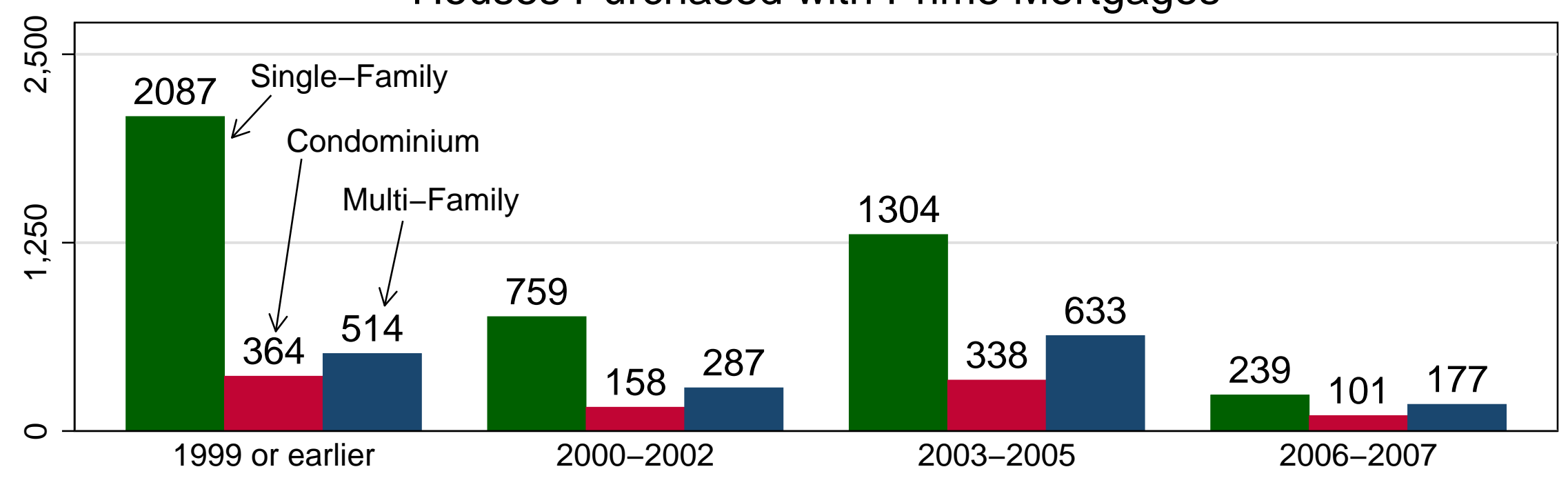

Houses Purchased with Subprime Mortgages

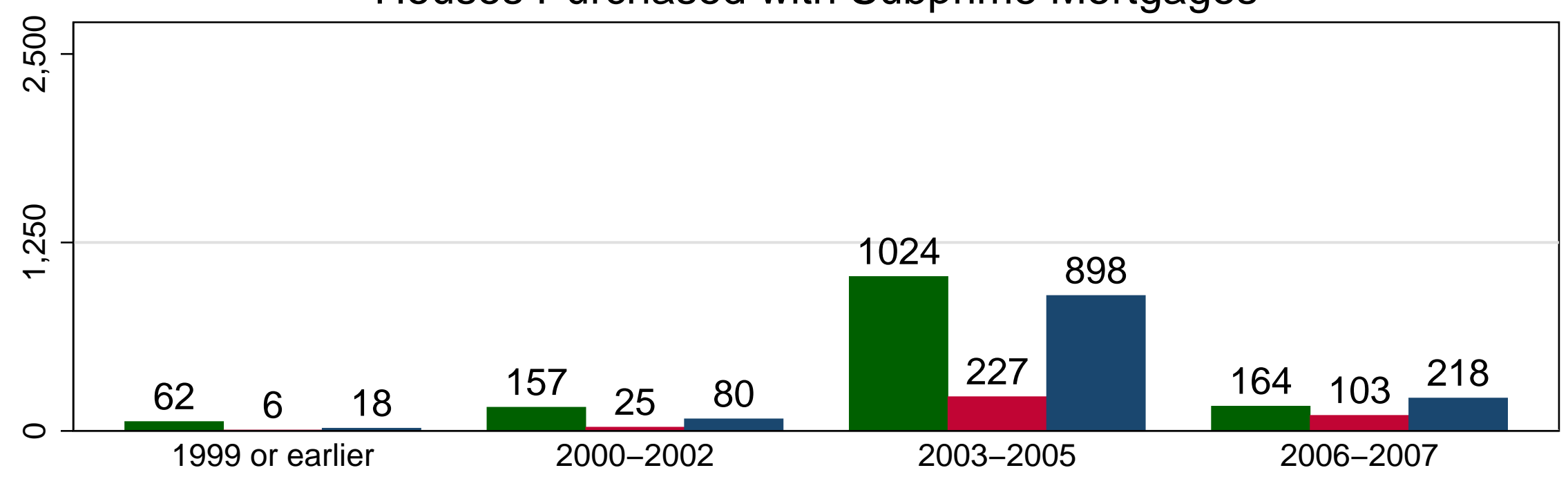


Figure 15 also confirms our other findings. We have already seen (in Figures 11 and 13) that foreclosure rates are high for homes purchased when prices were at their peak, because these homes never had a chance to amass much positive equity. As we would expect, Figure 15 confirms that homes purchased in 2003-2005 are strongly represented in 2006-2007 foreclosures. Additionally, Figure 15 illustrates the high rates of foreclosure among multifamily homes, particularly for multi-families purchased with subprime mortgages near the height of the recent boom (2003-2005). The absolute number of subprime multi-family foreclosures from the 2003-2005 cohort (898) is close to the number of subprime singlefamily foreclosures in that cohort (1024), even though the multi-family purchases were far less common than purchases of single-family homes in this period.

\subsection{Fact 7: Almost half of residential defaults in Massachusetts came on subprime mortgages, including subprime refinances of prime purchase mortgages}

Learning that many homes recently lost to foreclosure were purchased on or before 1999 confirms the importance of prime purchases in the current foreclosure wave. But this finding also raises an interesting question. According to our state-wide repeat-sales index, Massachusetts house prices have increased by more than 60 percent from 1999 to early 2008 . If positive equity forestalls foreclosure, why would any Massachusetts home purchased before 2000 suffer a foreclosure in 2006 or 2007? The most likely reason is that the homeowner extracted the equity from the home through one or more cash-out refinances as house prices rose.

Because the Warren Group data does not have the official mortgage-discharge records, we cannot measure equity extraction on foreclosed properties directly. We can, however, obtain a rough indication of whether equity extraction was taking place by counting the number of mortgages in ownership experiences that eventually end in foreclosure. A large number of mortgages for a single owner in a single house suggests higher refinancing activity and more opportunities for cash-out refinancing.

Table 9 shows that homes recently lost to foreclosure experienced higher refinancing activity than other homes, purchased at the same time, that have not yet been foreclosed upon or sold. The first row of the table measures the total number of mortgages for homes purchased in 1999. Homes that were purchased in that year and foreclosed upon in 2007 averaged 5.1 mortgages during their entire ownership experiences. For homes purchased in 1999 that have not yet been foreclosed upon or sold, the average number of lifetime mortgages is only 3.8. A similar discrepancy is present for homes purchased in 2000 through 
Table 9: Average Number of Lifetime Mortgages for Massachusetts Ownership Experiences, for Homes Purchased 1999-2007

\begin{tabular}{|c|c|c|c|c|c|c|c|c|c|c|c|}
\hline & \multicolumn{9}{|c|}{$\begin{array}{c}\text { Foreclosed Ownership Experiences, } \\
\text { by Year of Foreclosure }\end{array}$} & \multirow{2}{*}{$\begin{array}{c}\text { Non-Foreclosed } \\
\text { Ownership } \\
\text { Experiences }\end{array}$} \\
\hline & & 1999 & 2000 & 2001 & 2002 & 2003 & 2004 & 2005 & 2006 & 2007 & \\
\hline & 1999 & 1.6 & 1.6 & 1.6 & 1.8 & 2.2 & 2.6 & 3.5 & 4.3 & 5.1 & 3.8 \\
\hline & 2000 & & 1.5 & 1.4 & 1.6 & 1.8 & 2.1 & 3.0 & 4.1 & 4.9 & 4.1 \\
\hline & 2001 & & & 1.3 & 1.3 & 1.5 & 1.8 & 2.5 & 3.9 & 4.1 & 3.6 \\
\hline Year & 2002 & & & & 1.6 & 1.4 & 1.5 & 2.2 & 3.0 & 3.7 & 3.1 \\
\hline & 2003 & & & & & 1.3 & 1.2 & 1.8 & 2.3 & 3.0 & 2.4 \\
\hline Purchase & 2004 & & & & & & 1.1 & 1.6 & 2.0 & 2.4 & 2.2 \\
\hline & 2005 & & & & & & & 1.0 & 1.8 & 2.0 & 1.9 \\
\hline & 2006 & & & & & & & & 1.8 & 1.8 & 1.7 \\
\hline & 2007 & & & & & & & & & 1.6 & 1.4 \\
\hline
\end{tabular}

Note: Non-Foreclosed Ownership Experiences in the last column correspond to ownerships that had not ended with a sale by the end of 2007 .

2003.

Table 10: Average Number of Lifetime Subprime Mortgages for Massachusetts Ownership Experiences

\begin{tabular}{|c|c|c|c|c|c|c|c|c|c|c|}
\hline & \multicolumn{9}{|c|}{$\begin{array}{c}\text { Foreclosed Ownership Experiences, } \\
\text { by Year of Foreclosure }\end{array}$} & \multirow{2}{*}{$\begin{array}{c}\text { Non-Foreclosed } \\
\text { Ownership } \\
\text { Experiences }\end{array}$} \\
\hline & 1999 & 2000 & 2001 & 2002 & 2003 & 2004 & 2005 & 2006 & 2007 & \\
\hline 1999 & 0.2 & 0.1 & 0.1 & 0.3 & 0.4 & 0.5 & 1.2 & 1.2 & 1.6 & 0.2 \\
\hline 2000 & & 0.0 & 0.1 & 0.4 & 0.6 & 0.5 & 0.7 & 1.5 & 1.4 & 0.2 \\
\hline 2001 & & & 0.2 & 0.2 & 0.4 & 0.5 & 0.7 & 1.3 & 1.2 & 0.2 \\
\hline 2002 & & & & 0.3 & 0.2 & 0.5 & 0.7 & 1.1 & 1.2 & 0.2 \\
\hline 2003 & & & & & 0.3 & 0.3 & 0.8 & 1.0 & 1.1 & 0.2 \\
\hline 2004 & & & & & & 0.4 & 0.7 & 1.0 & 1.1 & 0.2 \\
\hline 2005 & & & & & & & 0.0 & 1.0 & 1.1 & 0.3 \\
\hline 2006 & & & & & & & & 0.8 & 0.9 & 0.2 \\
\hline 2007 & & & & & & & & & 0.1 & 0.0 \\
\hline
\end{tabular}

Note: Non-Foreclosed Ownership Experiences in the last column correspond to ownerships that had not ended with a sale by the end of 2007.

What role did subprime refinances play in these foreclosure patterns? Table 10 repeats this exercise but focuses only on the total number of subprime mortgages for various ownership experiences. The top row shows that homes that were purchased in 1999 and foreclosed upon in 2007 had an average of 1.6 subprime mortgages during their ownership experiences. The comparable number for homes purchased in 1999 that have not yet been foreclosed upon or sold is only 0.2 .

The role of subprime lending in cash-out refinancing and subsequent defaults helps rec- 
oncile the findings in this paper with those from other studies. We have found that in Massachusetts, most homes foreclosed upon in 2006-2007 were purchased with prime mortgages. But other studies show that subprime loans account for a large share of current defaults. Nothaft (2008), for example, uses data from the Mortgage Bankers Association's National Delinquency Survey to show that 52-56 percent of 2006-2007 defaults came on subprime loans. ${ }^{48}$ However, because of refinancing, loans that default today may not be the loans that were used to purchase homes. If prime borrowers often refinance with subprime loans before they default, then a high subprime share of current defaults is consistent with a lower subprime share among the purchase mortgages of foreclosed homes.

Table 11: Subprime Shares Among Defaulted Ownership Experiences and Mortgages, 2006-2007

\begin{tabular}{lcc}
\hline \hline & $\begin{array}{c}\text { Fraction of Defaulted } \\
\text { Ownerships Purchased } \\
\text { with Subprime Mortgages }\end{array}$ & $\begin{array}{c}\text { Subprime Fraction of } \\
\text { Defaulted Mortgages }\end{array}$ \\
\hline Single-Family & $24.3 \%$ & $42.2 \%$ \\
Condominium & $27.3 \%$ & $40.1 \%$ \\
Multi-Family & $43.0 \%$ & $53.3 \%$ \\
\hline All & $30.0 \%$ & $45.2 \%$ \\
\hline
\end{tabular}

Table 11 illustrates this pattern in the Warren Group data. The first column of the table reports the fraction of defaulted ownerships from 2006-2007 that were purchased with subprime mortgages. As we have seen, this fraction is 30 percent across all types of homes. The second column shows the percentage of defaulted mortgages from 2006-2007 that were originated by subprime lenders. Consistent with the other studies, this fraction is much higher. For all types of homes, the fraction is 45.2 percent. This number is close to, but somewhat lower than, the 52-56 percent rate that Nothaft (2008) found. The discrepancy of approximately 10 percentage points may reflect differences in the Massachusetts housing market relative to the rest of the country, or differences in the way that the two studies define subprime mortgages.

\section{Conclusion: Some outstanding questions}

We conclude with a discussion of outstanding questions relevant for the current housingpolicy debate:

\footnotetext{
${ }^{48}$ Nothaft (2008) finds that the precise subprime share of defaults varies by half-year period in 2006 and 2007. But the share for any single half-year period ranges between 52 to 56 percent in these two years.
} 


\section{- Were subprime ARMs good deals for subprime borrowers?}

Much of the criticism of subprime lending has focused on adjustable-rate mortgages (ARMs). We have seen that interest-rate resets on subprime ARMs are not the main problem in the subprime market, but subprime ARMs do warrant some scrutiny for several reasons. First, as seen in Figure 3, subprime ARMs have higher delinquency rates than subprime fixed-rate mortgages (FRMs). Secondly, as shown below in Appendix A, it is hard to find much difference in the initial interest rates paid on subprime ARMs and those paid on subprime FRMs. We would expect the initial rate on subprime ARMs to be substantially lower than rates on FRMs, because the ARM borrower should be compensated for the risk of future interest-rate increases. The higher default rates on subprime ARMs, along with the apparent lack of a compensating premium for interest-rate risk, suggest that subprime ARMs were not good deals for the borrowers that took them.

While this evidence against subprime ARMs is suggestive, we do not believe that it is conclusive. This is because the interest-rate and default patterns among subprime ARMs may have more to do with the types of borrowers that took ARMs, rather than the characteristics of the ARMs themselves. For example, the typical ARM borrower may be more tolerant of risk than the typical FRM borrower. This difference in risk-tolerance could play an important role in explaining why ARM borrowers default more often, as well as why they might have required only a small compensating premium for interest-rate risk. The fact that ARM and FRM borrowers differ on observable characteristics (such as credit score and willingness or ability to document income) suggests that these borrowers could also differ along unobservable dimensions as well. Moreover, the premium that ARM borrowers actually received may have been larger than we can measure with available data. Specifically, ARM borrowers might not have paid closing costs out-of-pocket when they originated their loans, instead folding them into the loan itself and thereby raising the contract interest rate. If FRM borrowers were less likely to do this, then the raw difference in initial rates on ARMs and FRMs could be quite small, even though the ARM borrowers were in fact receiving a substantial premium for interest-rate risk.

\section{- How many subprime borrowers were inappropriately "steered" into their mortgages?}

Recent press reports have argued that the presence of high-FICO borrowers in the subprime pool is prima facie evidence that they were steered into subprime loans by unscrupulous mortgage lenders, perhaps in search of higher commissions. The fact that high-FICO borrowers took out risky subprime loans undermines this claim, but it is still possible that subprime borrowers received poor advice from lenders or other real estate professionals. For 
example, borrowers could have been encouraged to stretch themselves into risky loans by lenders or real estate brokers, on the basis of inflated expectations of future house price increases. Related to the previous outstanding question, some subprime ARM borrowers may have not been fully informed about the risks they were taking on with their loans. The level of financial sophistication among subprime borrowers, and the quality of advice that these borrowers received, should be active areas of future research.

Figure 16: House Price Appreciation and Subprime-Purchase Lending in Massachusetts, 1988-2007

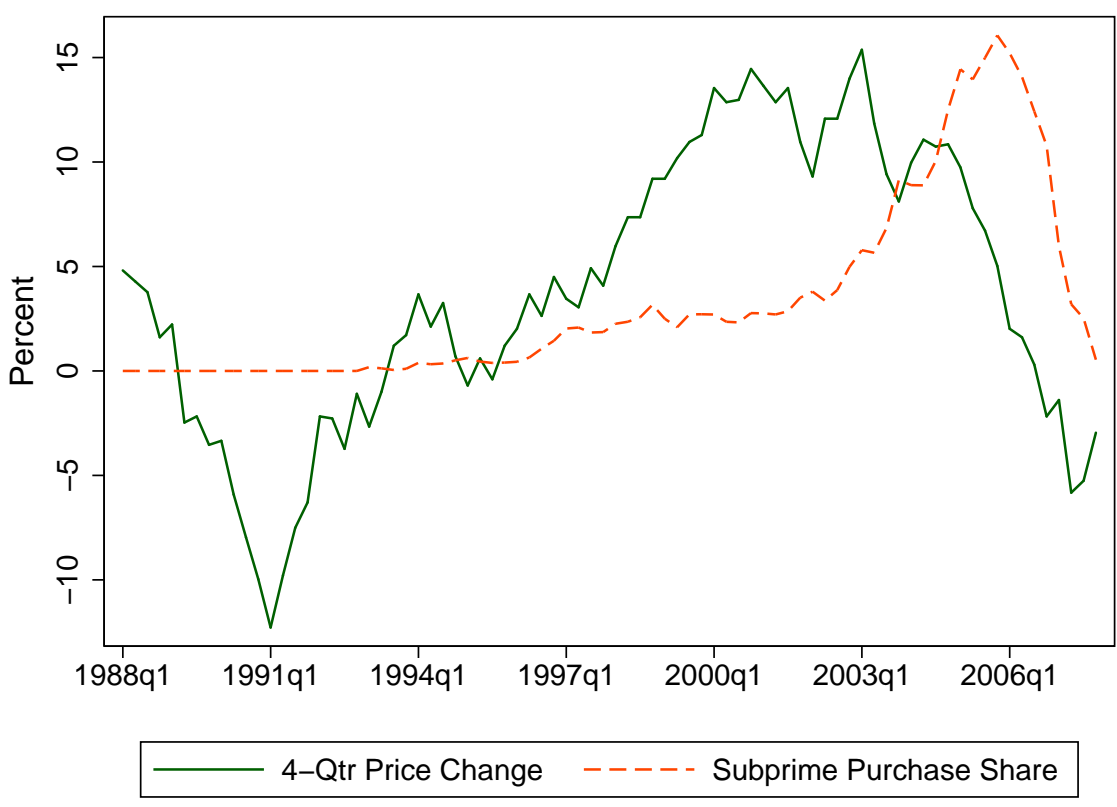

\section{- Did subprime lending cause the house-price boom of the early 2000s?}

The advent of subprime lending may have put upward pressure on prices during the recent housing boom in the United States. Such pressure could arise if subprime lending allowed more people to buy houses, or if it allowed existing buyers to bid higher amounts for home purchases. But the causality could run in the other direction, from higher housing prices to increased subprime lending. Using the Boston Fed's LP dataset, we saw that more and more high-FICO borrowers took out subprime loans as the housing boom progressed. One reason may have been that these borrowers wanted to buy expensive houses, and the subprime market was the only place that they could find the mortgages to do so. Another piece of evidence in favor of the alternative-causality story is that, at least in Massachusetts, housing prices started increasing well before subprime lending took off. Figure 16 shows that Bay State housing prices were rising by more than 10 percent per year by the year 
2000, when the subprime fraction of new purchases was still quite small. In short, figuring out the ultimate effect of subprime lending on house prices, and vice versa, is a difficult problem that will require innovative empirical approaches to answer.

\section{- Did subprime lending increase the homeownership rate?}

Subprime lending has complex effects on the national homeownership rate. Originally, subprime lending was thought to boost homeownership by extending mortgage finance to previously underserved populations. Aside from facilitating home purchases, subprime lending can also increase homeownership by preventing foreclosures. Recall that foreclosures occur when borrowers cannot make their mortgage payments and have no positive equity in their homes. To the extent that subprime lending facilitates refinances when equity is positive but small, then subprime refinances can prevent foreclosures that otherwise would have occurred. Of course, subprime lending could also have less favorable effects on homeownership. We have seen that some people who bought their homes with prime mortgages later refinanced into subprime mortgages and then defaulted. If subprime lending encourages owners to take "too much" equity out of their homes, so that they are in danger of having negative equity if house prices fall, then subprime lending can actually reduce the homeownership rate.

Quantifying the role of subprime lending therefore requires a better understanding of both subprime purchases and subprime refinances. Regarding purchases, we need to learn the extent to which subprime lending helps people who would have no other option if the subprime market did not exist. More difficult to know is the effect of subprime refinances on prime mortgages. How often do subprime refinances help homeowners get through difficult financial periods, and how often do these refinances actually cause difficult financial periods through the unwise extraction of equity? Answering these questions is difficult with current data, but doing so should be a goal of future research. 


\section{Appendix A Behavior of Subprime ARMs and FRMs}

An outstanding puzzle in subprime research involves the pricing of fixed-rate versus hybrid adjustable-rate mortgages. We would expect the initial interest rate for a hybrid ARM to be much lower than the interest rate on an FRM, because the ARM borrower is taking on interest-rate risk. If, in reality, the difference in rates between ARMs and FRMs is small, then policymakers may want to encourage borrowers to take a close look at FRMs as a way of reducing their risk exposure. In the data, initial rates on ARMs and FRMs are strikingly close. But it is hard to know whether subprime ARMs and FRMs are in fact mispriced to a degree that would warrant public policies encouraging subprime lenders to offer only fixed-rate mortgages.

Table A-1: Initial Interest Rate Differentials between Fixed-Rate and Adjustable-Rate Subprime Mortgages: 1998-2007

Interest Rate Differential:

Initial FRM Rate less Initial ARM Rate

(1) Raw Difference $\quad-0.086(0.042)$

(2) Controlling for borrower's FICO score

(3) Controlling for borrower's FICO score, presence of second mortgage, documentation status, and LTVs on first and second mortgages

(4) Controls as in previous row, using 2005-2007 data only

$0.163(0.015)$

Notes: Estimates are generated by Ordinary Least Sqaures (OLS) regressions of initial subprime interest rates on a dummy that equals 1 if the loan is a fixed-rate loan (and other controls as noted). All regressions include quarterly dummies. FICO score controls in rows 2-4 are piece-wise linear controls. Standard errors are in parentheses. Rows 1-3 cluster the standard errors by quarter. Row 4 does not, because of the small number of quarters available.

Table A-1 presents interest-rate differentials on FRMs versus ARMs from regressions run on 1998-2007 data from the Boston Fed's LoanPerformance dataset. ${ }^{49}$ Row 1 shows that the typical interest rate on a fixed-rate loan appears lower than the typical initial ARM rate when we perform a simple comparison of raw averages. This difference may not be the true cost of using a fixed-rate product, however, if there are systematic differences between borrowers that choose ARMs and those that choose FRMs. In fact, fixed-rate borrowers

\footnotetext{
${ }^{49}$ The data for the table come from subprime first-lien mortgages used for home purchases only.
} 
do tend to have better FICO scores and lower LTVs than ARM borrowers, and they are also more likely to fully document their mortgage applications. These good characteristics partially explain why FRM borrowers enjoy relatively low interest rates. Row (2) controls for differences in borrower credit histories by adding a flexible control for borrower FICO scores in the regression. The interest-rate differential turns positive and equals about 14 basis points. While this estimate is statistically significant, it is small in magnitude. ${ }^{50} \mathrm{In}$ row (3), we add some additional controls, but the difference remains quantitatively small. Finally, row (4) uses data from 2005-2007 only, but the regression again implies a small difference in interest rates of slightly more than 16 basis points.

This small differential is difficult to explain. One possible interpretation is that ARM borrowers do not bother to demand a risk premium because they expect to refinance before their resets hit. Alternatively, ARM borrowers could be more likely to fold their closing costs into their mortgages, paying these costs with a higher interest rate. If so, then the resulting increase in the ARM interest rate could mask a true rate differential between FRMs and ARMs that actual borrowers face in the market. Unfortunately, our data do not allow us to test this hypothesis directly.

Another puzzle between FRMs and ARMs concerns the rate at which these mortgages default when house prices fall. Figure A-1 shows estimated foreclosure probabilities for adjustable-rate and fixed-rate subprime mortgages during the first 24 months of the loans. ${ }^{51}$ The estimation procedure controls for FICO scores, LTVs, the presence of second mortgages, and documentation status; the gray bars in the figure are standard-error bands. The figure shows that when house prices grow rapidly (at more than 10 percent per year), there is no significant difference in foreclosure rates between FRMs and ARMs. ${ }^{52}$ However, as house price growth decelerates and falls below 10 percent, a difference does emerge. Moving from right to left in the figure, the average default rate on ARMs rises much more rapidly as prices fall than does the default rate on FRMs. Once house price growth becomes negative, the standard error bands no longer overlap, suggesting a statistically significant difference in foreclosure propensities between the two types of loans. ${ }^{53}$

\footnotetext{
${ }^{50} \mathrm{~A}$ difference of 14 basis points is only 14 one-hundredths of a percentage point, so this implies an adjustable-rate mortgage with an 8 percent interest rate could be replaced with a fixed-rate mortgage with an 8.14 percent interest rate.

${ }^{51}$ Unlike in GSW (2007), we do not model the full hazard of foreclosure for a mortgage. Instead, we collapse the data to just one observation per mortgage: the dependent variable is one if the mortgage went into foreclosure over the first 24 months, and zero otherwise. Like in Table A-1, the sample is restricted to first-lien mortgages for home purchases in Massachusetts, Rhode Island, and Connecticut.

${ }^{52}$ The standard error bars overlap, indicating that any difference may stem from statistical uncertainty surrounding the estimates.

${ }^{53} \mathrm{An}$ F-test on the profiles rejects equality at the 0.1 percent level.
} 
Figure A-1: Subprime Foreclosures and Cumulative House Price Changes: ARMs vs. FRMs

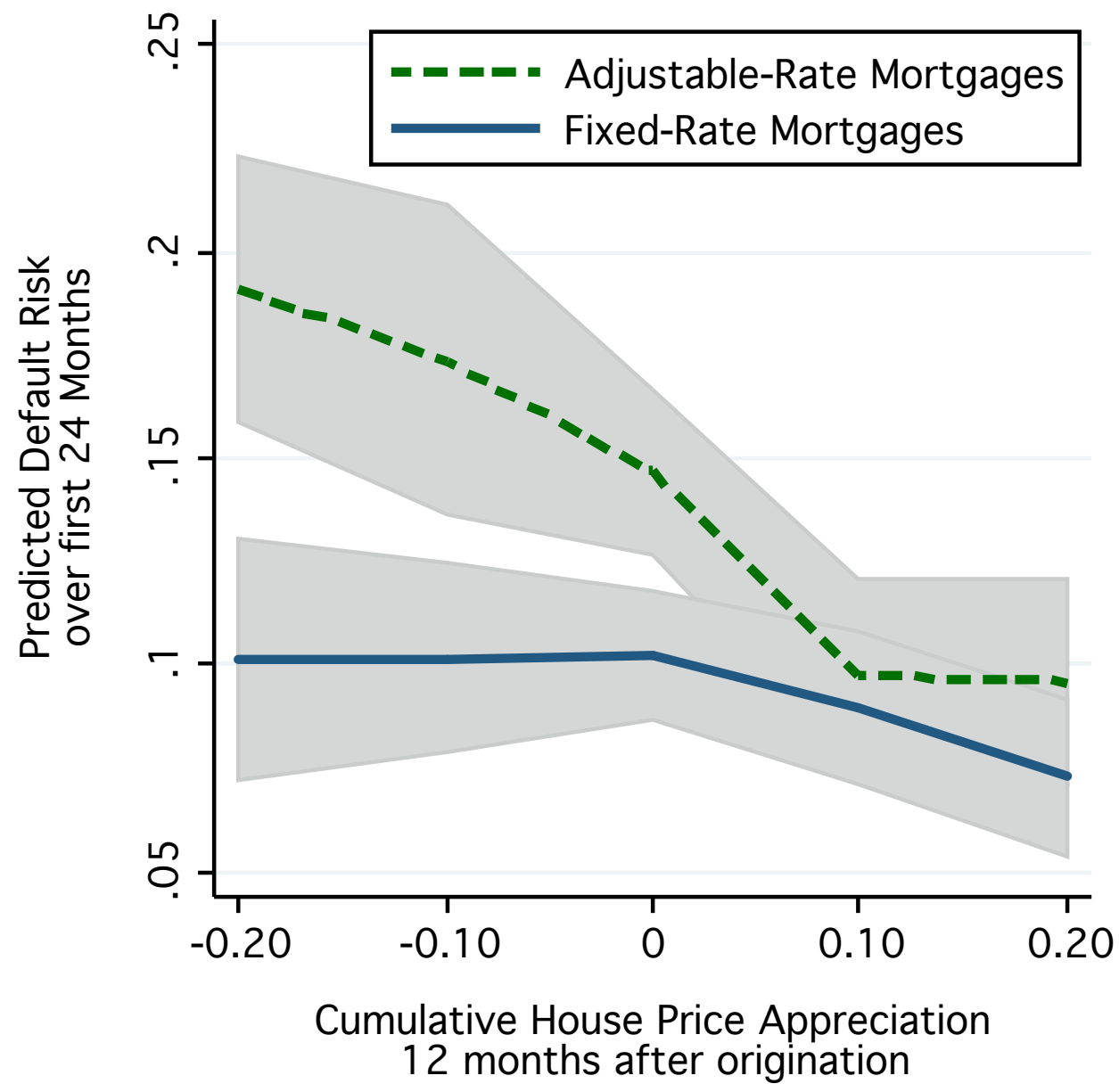

Notes: The figure shows estimated piece-wise linear profile of foreclosure rates over the first 24 months as a function of house price growth over the first 12 months, controlling for differences in FICO scores, LTV, second liens, and documentation status. Standard error bands around the profiles are calculated by clustering on quarters. The sample includes sub-prime first-lien mortgages used for purchases in Connecticut, Massachusetts, and Rhode Island (Boston Fed LoanPerformance data). 
Once again, ARM refinancing may underlie this feature of the data. Hybrid ARM borrowers might expect to refinance within the fixed-rate period of their mortgages. When house prices fall, these borrowers may (correctly) surmise that their chances to refinance have been reduced. If they know that they cannot afford the fully indexed interest rate, then they may default immediately. (Fixed-rate mortgages, by contrast, offer more flexibility in refinancing due to the lack of a specific reset date.) The implication is that the design of adjustable-rate mortgages may make them more vulnerable to changes in house prices than fixed-rate mortgages. Alternatively, the differences in default probabilities may result from the selection of particular borrowers into adjustable-rate loans. ARM buyers may have had higher expectations for future price appreciation than FRM borrowers. ARM borrowers may also be less "financially literate," with the implication that ARM borrowers are more likely to run into liquidity problems during periods of declining house prices than FRM borrowers. Financial literacy could also play a role in explaining the interest-rate patterns discussed earlier. If ARM borrowers are unable to quantify the degree of interest-rate risk they take on with an adjustable-rate product, then these borrowers may not demand to be compensated for this risk with lower initial interest rates.

\section{Appendix B Alternative Measures of Housing Prices}

As noted in the introduction, all references to price statistics in this paper are based on a repeat-sales index of house prices that we constructed using the Warren Group data. ${ }^{54}$ Figure B-1 compares our price index to the Massachusetts index constructed by the Office of Federal Housing Enterprise Oversight (OFHEO). The OFHEO index also uses the repeatsales method, but is based solely on purchases financed with agency-conforming mortgages. The two indexes are in strong general agreement during periods of overlap, though our index shows larger price declines during the two housing downturns of the past two decades. Figure B-2 compares our index with the S\&P/Case-Shiller repeat-sales index for Boston. This index includes non-conforming mortgages, but, as the name suggests, includes data only from the Boston area. Our index is in stronger agreement with the S\&P index during the two housing downturns, suggesting that the homes financed with non-conforming mortgages suffered larger price declines during these two periods.

\footnotetext{
${ }^{54} \mathrm{~A}$ town-level version of this index was also used in GSW (2007).
} 
Figure B-1: Statewide Repeat-Sales Index Constructed with Warren Group Data and OFHEO Price Index for Massachusetts

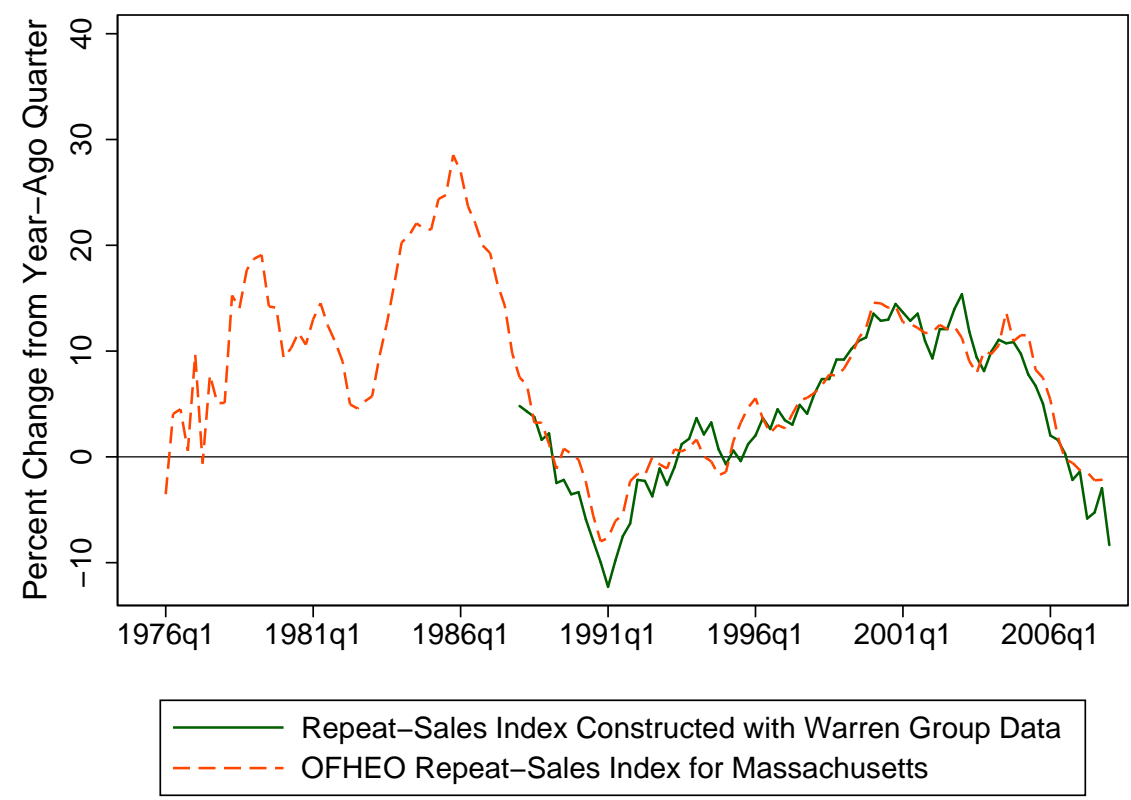

Figure B-2: Statewide Repeat-Sales Index Constructed with Warren Group Data and S\&P Case-Shiller Index for Boston

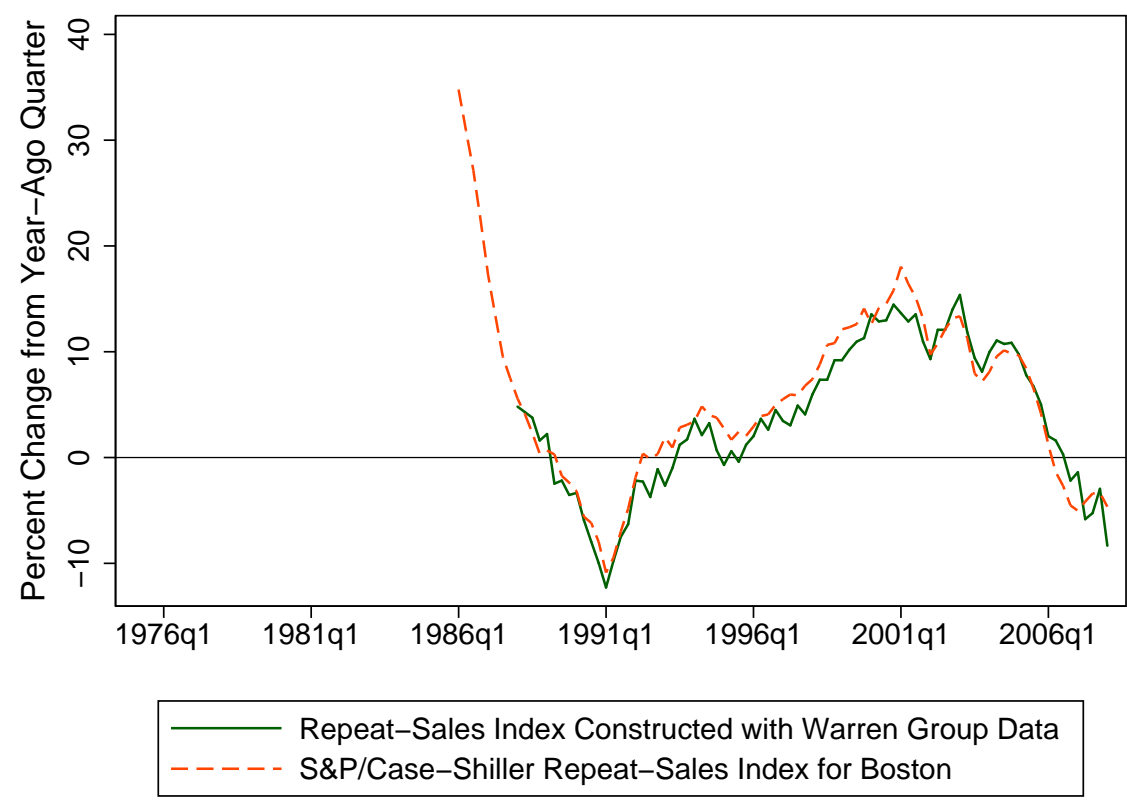




\section{References}

[1] Case, Karl, and Robert J. Shiller, 1987. "Prices of Single Family Homes Since 1970: New Indexes For Four Cities." NBER Working Paper No. 2393.

[2] Foote, Christopher L., Kristopher Gerardi, and Paul S. Willen, 2008. "Negative Equity and Foreclosure: Theory and Evidence," Federal Reserve Bank of Boston Working No. 08-03.

[3] Gerardi, Kristopher, Adam Hale Shapiro, and Paul S. Willen [GSW], 2007. "Subprime Outcomes: Risky Mortgages, Homeownership Experiences, and Foreclosures," Federal Reserve Bank of Boston Working Paper No. 07-15.

[4] Kau J., D. Keenan, and T. Kim, 1994. "Default Probabilities for Mortgages." Journal of Urban Economics 35: 278-296.

[5] Nothaft, Frank E., 2008. "The Mortgage and Housing Market Outlook," Presentation for the National Economists Club, March 27.

[6] Vandell K., 1995. "How Ruthless is Mortgage Default? A Review and Synthesis of the Evidence." Journal of Housing Research 6(2): 245-264. 